This item was submitted to Loughborough's Research Repository by the author.

Items in Figshare are protected by copyright, with all rights reserved, unless otherwise indicated.

\title{
How connected is the carbon market to energy and financial markets? A systematic analysis of spillovers and dynamics
}

PLEASE CITE THE PUBLISHED VERSION

https://doi.org/10.1016/j.eneco.2020.104870

\section{PUBLISHER}

Elsevier

VERSION

AM (Accepted Manuscript)

\section{PUBLISHER STATEMENT}

This paper was accepted for publication in the journal Energy Economics and the definitive published version is available at https://doi.org/10.1016/j.eneco.2020.104870.

LICENCE

CC BY-NC-ND 4.0

\section{REPOSITORY RECORD}

Tan, Xueping, Kavita Sirichand, Andrew Vivian, and Xinyu Wang. 2020. "How Connected Is the Carbon Market to Energy and Financial Markets? A Systematic Analysis of Spillovers and Dynamics". Loughborough University. https://hdl.handle.net/2134/12631382.v1. 


\title{
How Connected is the Carbon Market to Energy and Financial Markets? A Systematic Analysis of Spillovers and Dynamics
}

\author{
Xueping Tan ${ }^{a}$, Kavita Sirichand ${ }^{\mathrm{b}}$, Andrew Vivian ${ }^{\mathrm{b}^{*}}$, Xinyu Wang ${ }^{\mathrm{a}}$ \\ ${ }^{a}$ School of Management, China University of Mining \& Technology, Xuzhou, Jiangsu, China, 221116 \\ ${ }^{b}$ School of Business and Economics, Loughborough University, Loughborough, Leicestershire, UK, LE11 $3 T U$
}

\begin{abstract}
Carbon allowances are a new class of financial instrument which aim to assist in limiting the extent and impact of global warming and climate change. The feedback mechanism in the "CarbonEnergy-Finance" system makes the information connectedness dynamics more complex since we add equity, bond and non-energy commodity assets into the system. Using modified error variance decomposition and network diagrams, we quantify and systematically analyze how the European carbon market connects with information from a wide range of other markets. Our results indicate: (i) the nature of information spillover changes over time, with system-wide return connectedness being higher and more variable than the volatility interdependence; (ii) both the oil and carbon markets closely connect with equity and non-energy commodity markets rather than bond markets; (iii) we identify three structural breaks in carbon volatility and their implication for carbon-finance linkages; (iv) financial risk-type macroeconomic factors make greater contributions to system-wide connectedness than commodity factors. These findings have economic implications for investors, portfolio managers and policymakers.
\end{abstract}

Keywords: carbon market; financial markets; structural breaks; connectedness; error variance decomposition; macroeconomic determinants

Classification codes: G110; G130; G150; Q430 


\section{Introduction}

Since the establishment of the European Union Emissions Trading System (EU ETS) in 2005, carbon assets have attracted much attention from investors as useful investment vehicles for risk management (Subramaniam et al., 2015). For example, owing to the weak interactions between the carbon market and other conventional markets, especially during the periods of market turmoil (Koch, 2014), carbon assets tend to provide diversification benefits to energy commodities (Uddin et al., 2018), and taking short positions in carbon futures can be an attractive addition to equity portfolios (Graham et al., 2016). Additionally, as a policy-dominated market, the carbon market is a considerably specific market among energy commodities (Wei and Lin, 2016). For instance, European Union Allowances (EUA) futures have experienced sharp fluctuations throughout, partly because of a worsening global economic outlook (Wen et al., 2017) and interactions with other capital markets (Zhang and Sun, 2016; Balcilar et al., 2016). Thus, hedging the downside and upside risk of the carbon price with related assets is becoming an increasingly urgent task and essential for many heavy energy-using plants and industries. For example, Wen et al. (2017) find that coal (electricity) is the most (least) attractive in terms of mitigating the downside risk of carbon price. Furthermore, with the increase of globalization and carbon financialization (Berta et al., 2017), the strengthening feedback effects among the carbon market and other capital markets would imply a more vulnerable connectedness framework and higher systemic risk, which may lead to the failure of EU ETS. As a consequence, a rigorous investigation of the connectedness between the carbon market and other capital markets from a systemic perspective is absolutely necessary for investors (e.g., portfolio managers and covered companies) and policymakers of EU ETS. Therefore, we examine the following: (i) how does EUA interact with energy and non-energy financial assets in the "Carbon-Energy-Finance" system, and is EUA segmented? (ii) will EUA be better for diversification than crude oil in an investment portfolio with financial assets, and (iii) will the system-wide interactions be determined by any macroeconomic factors?

From a theoretical point of view, the carbon market is able to connect with other capital markets through two transmission channels. One channel is the correlated-information channel, also known as "return spillover", through which connections occur through the price-discovery process (Kodres and Pritsker, 2002). The other channel is the risk premium channel, also known as "volatility spillover", 
through which a shock in one market may adversely affect the willingness of market participants to hold risk in any markets (Acharya and Pedersen, 2005). Additionally, recent studies have demonstrated that fossil fuel prices can influence the carbon price directly via (i) the production restrain effect, (ii) the substitution effect, and (iii) the aggregated demand effect, but non-energy financial assets may influence the carbon allowance through a direct industrial production path and indirect energy price path (Tan and Wang, 2017). More specifically, in respect to the indirect energy price path, markets such as equity and bond markets are able to affect energy commodities via (i) the financial investment/speculation path ${ }^{1}$ (Tang and Xiong, 2012), and (ii) the traders' funding liquidity path ${ }^{2}$ (Brunnermeier and Pedersen, 2009), and (iii) the exchange rate path ${ }^{3}$ (Cashin et al., 2004). However, the linkages between energy and non-energy commodities can be explained by several paths including (i) Index funds (Irwin and Sanders, 2011), (ii) Biofuels (Chang and Su, 2010), and (iii) production costs and disposable income (Baffes, 2007). Therefore, it is necessary to explore both return and volatility connectedness in the "Carbon-Energy-Finance" system from a systemic perspective.

Until now, notable studies have investigated the specific connectedness of carbon market with energy markets including coal, oil, natural gas, and electricity, through various techniques, for example, Granger-causality tests (Keppler and Mansanet-Bataller, 2010); VAR (Kumar et al., 2012); the wavelet approach (Sousa et al., 2014); the bidimensional empirical mode decomposition (BEMD)-based multiscale approach (Yu et al., 2015); the multivariate generalized autoregressive conditional heteroskedasticity (MGARCH) techniques (Koch, 2014; Zhang and Sun, 2016); and the DieboldY1lmaz (DY) spillover index (Ji et al., 2018; Wang and Guo, 2018). However, the interactions between the carbon price and non-energy financial assets have not received sufficient attention, because the majority of studies have focused on stock markets (e.g., Creti et al., 2012; Kumar et al., 2012; Oestreich and Tsiakas, 2015; Tian et al., 2016; Graham et al., 2016). In particular, research on "Carbon-EnergyFinance" connectedness from a systemic perspective is incomplete. For instance, Koch (2014) investigates the dynamic volatility linkages in the "Carbon-Energy-Finance" system, including coal,

\footnotetext{
1 The rapidly growing investment in commodity markets (a form of financial speculation) since the early 2000, has resulted in increased price movements between various financial assets and commodities due to the strategic investment behavior of index investors.

2 Traders provide liquidity in commodity markets, and their ability to do so depends on their availability of funds.

3 The change in the exchange rate determines the purchasing power and thereby the consumers' demand for commodities, since the dollar is the benchmark pricing mechanism for most commodities.
} 
gas, oil, electricity, stock, and bonds, based on an MGARCH model with smooth transitions; however, it does not provide the directional connectedness information from a systemic perspective because the MGARCH method is only able to capture the pairwise correlation rather than directional system-wide interactions. In addition, structural breaks in the relationship between carbon assets and related assets have been discussed and identified in some prior literature (such as Koch, 2014; Wang and Guo, 2018); however, the evidence regarding the changes in network spillovers among the "Carbon-EnergyFinance" system caused by structural breaks is scarce. Finally, a link is suggested between the macroeconomy and the carbon price (Chevallier, 2011a), and the correlations of carbon-energy and carbonfinance heavily depend on uncertain market conditions because of common macroeconomic shocks during the financial crisis (Koch, 2014). However, little work has been done on examining the possible macroeconomic determinants of connectedness in the "Carbon-Energy-Finance" system, even though understanding the triggers of system-wide connectedness allows policymakers to derive an "earlywarning system" for identifying the potential systemic risk and to take appropriate regulatory actions as necessary.

By filling these gaps, this paper makes several important contributions to the literature. First, this study examines a more comprehensive system of "Carbon-Energy-Finance" system augmenting the widely examined "Carbon-Energy" system (e.g., Ji et al., 2018; Wang and Guo, 2018) by including three different asset classes, that is, non-energy commodity, equity, and bonds. This provides insight into the connection between the carbon, energy and financial markets. We find evidence of a close connectedness between the carbon market with some key financial markets (e.g., stock and non-energy commodity markets) and as such the carbon market is not (highly) segmented.

Second, we explore the system-wide static, rolling, and directional network connectedness in the “Carbon-Energy-Finance” system through the Modified Lanne-Nyberg DY spillover index method, which conducts the DY spillover index methodology based on a modified General Forecast Error Variance Decomposition (GFEVD) proposed by Lanne and Nyberg (2016) rather than the GFEVD of Pesaran and Shin (1998). A disadvantage of the original DY spillover index method is its reliance on Pesaran-Shin GFEVDs that do not sum to unity; this drawback is overcome in the Modified LanneNyberg DY spillover index method (Chan-Lau, 2017). Thus, the comparison of the information contribution and the ranking of a member in the system at two different points in time are robust. 
Moreover, different from the traditional econometric methods (e.g., Granger-causality, VAR, and MGARCH) in the literature, the Modified Lanne-Nyberg DY spillover index method captures both the magnitude and direction of the static and dynamic connectedness in the system, which enables market participants to comprehend the information transmission mechanism and identify the main risk triggers of each member in the system.

Third, as two different commodities with distinctive characteristics, the carbon allowance and crude oil may connect with financial assets in a unique manner; thus, the connectedness features of carbon-finance and oil-finance are compared and analyzed in detail. Surprisingly, our study finds that both the carbon-finance and oil-finance linkages are weaker than the average level of the "CarbonOIL-Finance" system. By comparison, the connectedness of oil with stock and non-energy commodities is much larger than that of EUA, and neither of them closely interacts with bond markets.

Fourth, many studies have demonstrated that structural breaks play a critical role in price and volatility forecasting (e.g., Tan and Wang, 2017; Ewing and Malik, 2017; Wang and Wang, 2019), and that the connectedness of EUA with energy prices is sensitive to extreme events (Wang and Guo, 2018). Thus, we divide the full sample into four sub-samples according to the three structural breaks detected through the iterated cumulative sum of the squares (ICSS) algorithm of Inclan and Tiao (1994) and analyze the influences of structural breaks on the carbon-finance linkages with the aid of network diagrams. We find significant structural breaks, especially during 2010, in EUA unconditional volatility which substantially impacts both return and risk spillovers in the system.

Finally, we compare the contributions of commodity-type macroeconomic factors and financial risk-type macroeconomic factors to the system-wide connectedness through Shapley's (1953) measure. To our knowledge we are the first to explore the macroeconomic drivers of system-wide dynamic connectedness in the context of the "Carbon-Energy-Finance" system. Surprisingly, we find the contributions of commodity-type macroeconomic factors are much stronger than financial risk-type macroeconomic factors. Notably, the US dollar index, VIX and global economic policy uncertainty index generate considerable influences on the overall connectedness in the system. This new finding provides important signals for systemic risk monitoring.

The remainder of the paper is organized as follows. Section 2 reviews the related literature. Section 3 introduces the empirical methodology. Section 4 describes the variables and data with some 
preliminary analysis. Section 5 presents the empirical findings, and Section 6 concludes the paper.

\section{Literature review}

With the increasing globalization, the asset-level diversification displays more advantages over the country-level diversification in terms of efficient portfolios (Singh et al., 2019). Since the start of the EU ETS, interest in studying carbon markets from a financial point of view has increased. At the asset level, many studies have already analyzed the return connection between carbon allowance and energy (e.g., recent papers by Aatola et al., 2013; Reboredo, 2013; Sousa et al., 2014; Hammoudeh et al., 2015; Boersen and Scholtens, 2014; Yu et al., 2015; Marimoutou and Soury, 2015; Kanamura, 2016; Wen et al., 2017), and non-energy financial assets (Chevallier, 2009; Chevallier, 2011b; Kumar et al., 2012; Creti et al., 2012; Oestreich and Tsiakas, 2015; Zheng et al., 2015; Tian et al., 2016; Tan and Wang, 2017), whereas only very recently have authors focused on the volatility spillovers between the carbon market and other capital markets (e.g., Reboredo, 2014; Koch, 2014; Zhang and Sun, 2016; Balcılar et al., 2016; Wei and Lin, 2016; Ji et al., 2018; Wang and Guo, 2018).

Specifically, for carbon-energy linkages, Mansanet-Bataller et al. (2007) and Alberola et al. (2008) were the first to econometrically uncover the relations between energy markets and the carbon price. Based on the spot and futures data during the Phase I, the former studies find that carbon prices in the EU ETS are linked to fossil fuel (e.g., oil, gas, coal) use. By using a structural, co-integrated vector error-correction model, Bunn and Fezzi (2008) quantify the interactions of UK electricity, gas, and carbon prices, derive the dynamic pass-through of carbon prices into electricity prices, and the response of electricity and carbon prices to shocks of gas prices. Based on Granger-causality tests, Keppler and Mansanet-Bataller (2010) demonstrate that coal and gas prices impact EUA future prices through the dark and spark spread, and in return EUA prices Granger cause electricity prices during the Phase I of the EU ETS. Some studies focus on the nonlinear linkages of carbon-energy, for example, Zachmann (2013) finds that nonlinear interaction among fuel, carbon and electricity prices, where electricity prices can be explained by a changing linear combination of fuel and carbon prices. Hammoudeh et al. (2015) demonstrate the long-term negative impact of crude oil prices on EUA prices by using a nonlinear autoregressive distributed lag model. Considering the interactions may vary from the frequency domain, using a multivariate wavelet analysis, Sousa et al. (2014) find $\mathrm{CO}_{2}$ leads 
electricity variables in the time-frequency domain, and observe a high partial coherency of $\mathrm{CO}_{2}$ electricity (with $\mathrm{CO}_{2}$ leading) and $\mathrm{CO}_{2}$-coal (with coal leading). Moreover, through a BEMD-based multiscale approach, Yu et al. (2015) find a strong bidirectional linear and nonlinear spillover effect between the carbon and crude oil markets. As for the tail dependence, Marimoutou and Soury (2015) model the tail linkages between carbon allowance spot prices and a set of commodity prices through copulas, while Tan and Wang (2017) characterize the tail linkages between carbon futures and the energy prices using quantile regressions.

In terms of carbon-finance linkages, Oberndorfer (2009) is the first to address this from the angle of the stock markets. Subsequently, Chevallier (2009) examines the macroeconomic determinants of EUA prices and reports a weak association between carbon prices and stock and bond variables. Furthermore, using a Factor-Augmented Vector Autoregression model with latent factors extracted from 115 macroeconomic, financial, and commodities indicators, Chevallier (2011b) investigates the responses of several types of carbon prices to exogenous shocks, to that the factor correlated with commodities markets has the highest explanatory power, explaining approximately $28 \%$ of the total variability. More recently, Yu and Mallory (2014) reveal the depreciation (appreciation) of European currencies can also cause lower (higher) carbon prices through alternative energy mechanisms. Zheng et al. (2015) uncover some common characteristics of EUA as a financial asset, and demonstrate that the investment behavior of investors is one of most important factors that affect the price of EUA and other assets because of the significant cross-correlations between EUA and a wide range of financial assets (i.e., stock, currency and commodity). Some studies have provided evidence on the linkages between European carbon prices and electricity stock returns (Oberndorfer, 2009; Tian et al., 2016) and argue that emission prices introduce additional costs to power generators, resulting in more volatility in their cash flows. Furthermore, using the quantile regression method, Tan and Wang (2017) uncover both energy prices and financial risk factors (i.e., equity, commodity, T-bill, and Junk bond) have significant impacts on the carbon price during the three phases of the EU ETS, most notably, the changes in stock price and T-Bill rate may lead sharp falls in the carbon price.

In addition, recent studies have examined the volatility linkages between carbon and related fundamentals using various MGARCH models. More recently, for example, Chevallier (2012) tests the ability of multivariate GARCH models such as BEKK, CCC, and DCC to capture the dynamic 
correlations between oil, gas and $\mathrm{CO}_{2}$ variables. Koch (2014) finds evidence favoring closer carbonenergy linkages in the second phase of the EU ETS, with expectations of high stock market volatility significantly increasing the carbon-stock correlation under Smooth Transition Conditional Correlation GARCH models. Using similar models, Zhang and Sun (2016) demonstrate some significant volatility spillovers and correlations between carbon prices and three energy prices (i.e. coal, natural gas, and Brent crude oil). Balcilar et al. (2016) find evidence of significant volatility and time-varying risk transmission from the energy to the carbon market under a MS-DCC-GARCH model. Based on the BEKK-GARCH models, Wei and Lin (2016) suggest that carbon price volatility is directly affected by its own volatility and indirectly affected by the volatility of oil and stock returns via the covariance term.

The literature examining return linkages using traditional methods fails to provide insight into the time-varying connectedness between carbon price and other assets. However, based on the information contained in the variance-covariance matrix, the MGARCH models are able to capture the dynamic correlations instead of directional spillovers (Awartani and Maghyereh, 2013). The wavelet-based analysis, as outlined in the previous literature (e.g., Ranta, 2013; Khalfaoui et al., 2015), operates in the time-frequency domain and examines the coherency of variables and lead-lag relationship at different frequencies for different time periods, and displays obvious advantages in capturing market integration and contagions (Das et al., 2018; Torrence and Compo,1998); however, it does not reveal the time-varying net contribution of each variable to the system/or other variables. Based on this information, using the DY spillover index proposed by Diebold and Y1lmaz $(2009,2012,2014)$ from a variance decomposition perspective, Ji et al. (2018) investigate the dynamic returns and volatility spillovers in the "Carbon-Energy" system and find crude oil, clean energy, and coal play a dominant role in both the returns and volatility systems, with the electricity market being the main net return and volatility receiver. Using the same method, Wang and Guo (2018) importantly uncover that the WTI oil market transmits the strongest spillover effect to the system, and the carbon market generally plays the role of return spillover receiver and volatility spillover transmitter. However, these studies do not consider the return and volatility connectedness between carbon and non-energy financial assets. Additionally, Zheng et al. (2015) investigate the common features of EUA as a financial asset, and demonstrate that the EUA is different from currency futures and commodity futures because the EUA 
has a weaker correlation with financial assets and commodity assets; however, few examples in the literature have compared the connectedness of carbon-finance with that of oil-finance. Furthermore, numerous studies (e.g., Koch, 2014; Zhu et al., 2015; Tan and Wang, 2017; Wang and Guo, 2018) find several structural breaks in the interactions between the carbon allowance and related assets, but none investigate the influence of structural breaks on the spillover network of the "Carbon-Energy-Finance" system. Finally, Koch (2014) provides clear evidence that the interactions between carbon and related assets may depend on uncertain market conditions. For instance, volatility in aggregated industrial production in the EU 27 (Chevallier, 2011a), VIX (Koch, 2014), along with major policy changes and events (Wang and Guo, 2018) may result in structural breaks of the spillover index since these factors are triggers of investor sentiment (Zheng et al., 2015). However, few examples in the literature have investigated the contribution of each possible macroeconomic factor to the overall return and volatility connectedness in the "Carbon-Energy-Finance" system. Here, we address these gaps by exploring network connectedness within a comprehensive system. Knowledge and understanding of the timedependent dynamics, hierarchy, direction, intensity, structural breaks, and macroeconomic determinants of the spillovers in the "Carbon-Energy-Finance" system, is essential for market participants and policymakers alike.

\section{Methodology: Diebold-Yılmaz Spillover Index with Lanne-Nyberg GFEVD}

The DY spillover index proposed by Diebold and Y1lmaz $(2009,2012,2014)$ is widely used to examine the directional connectedness of variables. Diebold and Y1lmaz (2014) modify the spillover index to overcome the VAR variables ordering issue; however, due to the fact that the GFEVD contributions do not add up to unity as the error terms are correlated, more attention should be paid to two potential issues which include: (i) how to interpret the shocks to the system economically (Koop et al., 1996), and (ii) how best to assess changes in the systemic contribution of an individual variable over time (Chan-Lau, 2017). To address these concerns, Lanne and Nyberg (2016) propose a modified GFEVD which makes the relative contributions to the h-period impact of the shocks to sum to unity. Therefore, following Chan-Lau (2017), here we employ the Modified Lanne-Nyberg DY (thereafter MLNDY) variance decomposition network to calculate the directional connectedness in the "CarbonEnergy-Finance" system. 
For generality, following Pesaran and Shin (1998), we consider a K-dimensional nonlinear multivariate model

$$
y_{t}=G\left(y_{t-1}, \ldots, y_{t-p} ; \theta\right)+\varepsilon_{t}
$$

where $G(\cdot)$ is a nonlinear function depending on the parameter vector $\theta$ and $\varepsilon_{t}$ is an iid error term. Here, we concentrate on shocks hitting only one equation at a time, and define the General Impulse Response Function (GIRF) of $y_{t}$ to the shock $\delta_{j t}$ at horizon $\quad l$ as:

$$
G I\left(l, \delta_{j t}, \varpi_{t-1}\right)=E\left(y_{t+l} \mid \varepsilon_{j t}=\delta_{j t}, \varpi_{t-1}\right)-E\left(y_{t+l} \mid \varpi_{t-1}\right), l=0,1,2, \ldots
$$

where $\varpi_{t-1}$ and $\delta_{j t}$ are the history and the shock to the $j$ thequation that the expectations are conditioned on, respectively. The GIRF in Eq. (2) can be interpreted as the time profile of the effect of the shock $\delta_{j t}$ hitting at time ${ }_{t}$, obtained as the difference between the expectations conditional on the shock and the history $\varpi_{t-1}$, and the expectations conditioned only on the history $\varpi_{t-1}$. Each history $\varpi_{t-1}$ consists of the matrix of initial values needed to compute the two conditional expectations (forecasts) which are typically obtained by averaging a large number of realizations from Eq. (1) with and without the shock $\delta_{j t}$, respectively (for details on the procedure of the shocks, see Koop et al. (1996)).

Different from the Pesaran-Shin GFEVD based on the orthogonalized impulse response function, the Lanne-Nyberg GFEVD is not restricted to the linear $\operatorname{VAR}(p)$ model with normally distributed errors, and is constructed by replacing the orthogonalized IRF in Pesaran-Shin GFEVD with the GIRF shown in Eq. (2) (see Section 2 of Lanne and Nyberg (2016) for more information). The corresponding LanneNyberg GFEVD component for horizon $h$ equals

$$
\lambda_{i j, \omega_{t-1}}(h)=\frac{\sum_{l=0}^{h} G I\left(l, \delta_{j t}, \varpi_{t-1}\right)}{\sum_{j=1}^{K} \sum_{l=0}^{h} G I\left(l, \delta_{j t}, \varpi_{t-1}\right)_{i}^{2}}, i, j=1, \ldots, K .
$$

here $j$ and $i$ refer to shock and variable, respectively, $h$ is the horizon and $\varpi_{t-1}$ denotes the history. The denominator estimates the aggregate cumulative effect of all the shocks, whereas the numerator is the cumulative effect of the $j$ th shock. By construction, $\lambda_{i j, \omega_{t-1}}(h)$ lies between 0 and 1 , measuring the relative contribution of a shock to the $j$ th equation in relation to the total impact of all K shocks on the $i$ th variable in $y_{t}$ after $h$ periods, and these contributions sum to unity.

In the linear VAR model with infinite-order moving-average representation $y_{t}=\sum_{j=0}^{\infty} A_{j} \varepsilon_{t-j}$, with 
no identification restrictions imposed, the GIRF in Eq.(2) reduces to $G I\left(l, \delta, \varpi_{t-1}\right)=\mathrm{A}_{l} \delta$, which is independent of history $\varpi_{t-1}$, but depends on the hypothetical $K \times 1$ vector of shocks of size $\delta=\left(\delta_{1}, \ldots, \delta_{K}\right)^{\prime}$, with only one of the elements non-zero. Assuming normality of the error term $\varepsilon_{t}$ and setting a shock to the $j$ th element of $\varepsilon_{t}$, the unscaled GIRF of the shock $\delta_{j}$ is given by:

$$
G I\left(l, \delta_{j}, \varpi_{t-1}\right)=\mathrm{A}_{l} \sum e_{j} \sigma_{j j}^{-1} \delta_{j}
$$

Then, following Chan-Lau (2017) and Diebold and Y1lmaz (2012), the MLNDY total spillover index (thereafter "TOTAL"), which measures the contribution of spillovers of shocks across the variables to the total forecast error variance, is then constructed as:

$$
S^{L N}(h)=\frac{\sum_{\substack{i, j=1 \\ i \neq j}}^{K} \lambda_{i j, \omega_{t-1}}(h)}{\sum_{i, j=1}^{K} \lambda_{i j, \Phi_{t-1}}(h)} \cdot 100=\frac{\sum_{\substack{i, j=1 \\ i \neq j}}^{K} \lambda_{i j, \sigma_{t-1}}(h)}{K} .100
$$

The MLNDY directional spillover index imparted by all other variable $j$ to variable $i$ (thereafter "FROM") is measured as:

$$
S_{i \bullet}^{L N}(h)=\frac{\sum_{\substack{j=1 \\ j \neq i}}^{K} \lambda_{i j, \omega_{t-1}}(h)}{\sum_{j=1}^{K} \lambda_{i j, \omega_{t-1}}(h)} \cdot 100
$$

In a similar vein, the MLNDY directional spillover from variable $i$ to all other variable $j$ (thereafter "TO") is calculated as:

$$
S_{\bullet i}^{L N}(h)=\frac{\sum_{\substack{j=1 \\ j \neq i}}^{K} \lambda_{j i, \omega_{t-1}}(h)}{\sum_{j=1}^{K} \lambda_{j i, \omega_{t-1}}(h)} .100
$$

Correspondingly, given these directional spillovers, the MLNDY net spillovers (thereafter "NET") from variable $i$ to all variable $j$ can be calculated as the difference between gross shocks transmitted to ("TO") and gross shocks received from all other variables (“FROM"):

$$
S_{i}^{L N}(h)=S_{\bullet i}^{L N}(h)-S_{i \bullet}^{L N}(h)
$$

Under this logic, a MLNDY net directional spillover measure for each pair (thereafter "NET PAIRWISE") can be constructed as: 


$$
S_{i j}^{L N}(h)=\left(\frac{\lambda_{i j, \omega_{t-1}}(h)}{\sum_{k=1}^{K} \lambda_{i k, \omega_{t-1}}(h)}-\frac{\lambda_{j i, \omega_{t-1}}(h)}{\sum_{k=1}^{K} \lambda_{j k, \omega_{t-1}}(h)}\right) \cdot 100
$$

\section{Data}

We consider daily data of ten assets from $4^{\text {th }}$ March, 2008, to $17^{\text {th }}$ July, 2018, giving 2651 observations ${ }^{4}$. This spans almost the entirety of Phase II and all of Phase III of the EU ETS so far; it includes several important energy and financial market episodes (e.g., the 2007 US subprime mortgage crisis and European sovereign debt crisis from 2009 onward). We exclude the Phase I period ${ }^{5}$ because an extensive stream of the literature has already demonstrated that the reason for the peculiar allowance price movement (increased to over $€ 30$ initially and then collapsed to essentially zero by the beginning of 2008) in Phase I is due to policy adjustments in the EU ETS instead of market fundamentals (Benz and Trück, 2009).

We employ the continuous settlement prices (denominated in EUR/ton of $\mathrm{CO}_{2}$ ) of the ICE-EUA futures contract as the carbon market variable (denoted by EUA). Next, four energy variables are adopted to represent different energy markets, which include the continuous settlement prices of ICEBrent Crude Continuous futures ${ }^{6}$ (USD/barrel; OIL), ICE-API2 Rotterdam Coal futures ${ }^{7}$ (USD/ton; COAL) and ICE-UK Natural Gas futures ${ }^{8}$ (Sterling and pence/Therm; GAS), and EEX-Phelix Electricity Baseload futures ${ }^{9}$ (EUR/MWh; EPE). To ensure that the aforementioned energy assets are traded in the same currency, we have converted foreign currencies to EUR by using the daily exchange rates from the European Central Bank. We rely on five Non-energy financial risk variables to reveal the price information of different financial markets. Specifically, the S\&P GSCI Non-Energy

\footnotetext{
${ }^{4}$ From an econometric point of view, our dataset of 10 years length of daily data is sufficient to yield meaningful estimation results. To check the robustness of our empirical results using daily data and given the documented merit of using weekly data (e.g., see Sadorsky, 2014; Khalifa et al., 2014; Antonakakis and Kizys, 2015; Batten et al., 2015), we re-estimate using weekly data, namely Wednesday observations, see Appendix B3.

5 To check our results for sensitivity to the sample period, we report the results with the sample that includes Phase I in the EU ETS in Appendix B1.

6 ICE-Brent Crude Continuous futures provide the reference crude oil price benchmark for two thirds of the world's internationally traded crude oil supplies, especially the ones in Europe.

7 Rotterdam Coal futures price is regarded as the primary reference coal price for northwest Europe and a vital fundamental reference of the monthly average API2 Index as published in Argus/ McCloskey's Coal Price Index Report.

${ }^{8}$ ICE-UK daily Natural Gas 1-Month Forward contract is the most-used liquid natural gas derivative instrument for gas market pricing in Europe.

${ }^{9}$ EEX-Phelix Electricity future is established as the benchmark contract for European power because it is the most liquid contract for European power with fast growing open interest and trading volumes for maximum liquidity.
} 
Commodity Index Return ${ }^{10}$ (NCIR) is used to represent the commodity market; Euro corporate bond return spread $^{11}$ (ECRS), defined as the excess of the return on FISE euro corporate bonds rated BBB over the return on the AAA rated bonds, is adopted to capture the dynamics of the European junk bond market. Further, two points on the EU government AAA rated yield curve are considered, namely, the 3-month T-bills ${ }^{12}$ (ESTB) and the 10-year bonds ${ }^{13}$ (ELTB), Finally, for the behavior of stock returns, we consider the STOXX EUROPE $600 \operatorname{Index}^{14}(\text { ESTOXX) })^{15}$.

Table 1 Preliminary statistics of daily return and volatility.

\begin{tabular}{|c|c|c|c|c|c|c|c|c|c|c|}
\hline Obs. $=2651$ & EUA & COAL & OIL & GAS & EPE & NCIR & ELTB & ECRS & ESTOXX & ESTB \\
\hline \multicolumn{11}{|c|}{ Panel A: Returns } \\
\hline Mean & -0.00006 & -0.00006 & -0.00006 & -0.00002 & 0.00008 & -0.00029 & -0.00139 & 0.00010 & 0.00008 & -0.00174 \\
\hline Median & 0.00000 & 0.00017 & -0.00014 & -0.00094 & 0.00259 & -0.00005 & -0.00236 & 0.00011 & 0.00044 & -0.00044 \\
\hline Max & 0.245 & 0.083 & 0.114 & 0.356 & 1.734 & 0.059 & 0.260 & 0.013 & 0.094 & 0.223 \\
\hline Min & -0.431 & -0.098 & -0.117 & -0.126 & -2.571 & -0.058 & -0.193 & -0.011 & -0.079 & -0.940 \\
\hline Std. Dev. & 0.031 & 0.016 & 0.021 & 0.027 & 0.101 & 0.010 & 0.041 & 0.002 & 0.013 & 0.031 \\
\hline Skewness & -0.819 & -0.430 & -0.042 & 2.157 & -8.393 & -0.348 & 0.265 & 0.172 & -0.170 & -11.726 \\
\hline Kurtosis & 20.731 & 8.280 & 6.335 & 28.553 & 274.332 & 7.121 & 5.088 & 14.066 & 9.918 & 335.133 \\
\hline J-B & $34997^{* * *}$ & $3158^{* * *}$ & $1228^{* * *}$ & $74181^{* * *}$ & $8163196^{* * *}$ & $1927^{* * *}$ & $511^{* * *}$ & $13528^{* * *}$ & $5295^{* * *}$ & $12236455^{* * *}$ \\
\hline$Q(30)$ & $158.77^{* * *}$ & $169.25^{* * *}$ & $76.179^{* * *}$ & $81.491^{* * *}$ & $162.66^{* * *}$ & 28.9 & $55.525^{* * *}$ & $155.77^{* * *}$ & $69.639^{* * *}$ & $368.93^{* * *}$ \\
\hline ADF test & $-39.908^{* * *}$ & $-43.204^{* * *}$ & $-56.061^{* * *}$ & $-49.888^{* * *}$ & $-33.193^{* * *}$ & $-52.173^{* * *}$ & $-48.240^{* * *}$ & $-23.876^{* * *}$ & $-25.816^{* * *}$ & $-9.361^{* * *}$ \\
\hline \multicolumn{11}{|c|}{ Panel B: Volatility } \\
\hline Mean & 0.02124 & 0.01074 & 0.01506 & 0.01753 & 0.03116 & 0.00674 & 0.03036 & 0.00107 & 0.00849 & 0.01436 \\
\hline Median & 0.01483 & 0.00759 & 0.01044 & 0.01185 & 0.00994 & 0.00478 & 0.02392 & 0.00067 & 0.00572 & 0.00833 \\
\hline Max & 0.431 & 0.098 & 0.117 & 0.356 & 2.571 & 0.059 & 0.260 & 0.013 & 0.094 & 0.940 \\
\hline Min & 0.000 & 0.000 & 0.000 & 0.000 & 0.000 & 0.000 & 0.000 & 0.000 & 0.000 & 0.000 \\
\hline Std. Dev. & 0.023 & 0.011 & 0.015 & 0.021 & 0.096 & 0.007 & 0.027 & 0.001 & 0.009 & 0.028 \\
\hline Skewness & 4.235 & 2.670 & 2.176 & 5.220 & 14.660 & 2.352 & 1.821 & 3.635 & 2.945 & 17.255 \\
\hline Kurtosis & 49.041 & 13.456 & 9.765 & 61.868 & 315.793 & 11.685 & 8.632 & 21.896 & 17.260 & 501.375 \\
\hline J-B & $241885^{* * *}$ & $15214^{* * *}$ & $7141^{* * *}$ & $393280^{* * *}$ & $191654^{* * *}$ & $10768^{* * *}$ & $4965^{* * *}$ & $45246^{* * *}$ & $26274^{* * *}$ & $27546175^{* * *}$ \\
\hline Q (30) & $2831.8^{* * *}$ & $3073.4^{* * *}$ & $3975.8^{* * *}$ & $1628.2^{* * *}$ & $437.11^{* * *}$ & $2514.4^{* * *}$ & $633.56^{* * *}$ & $4233.9^{* * *}$ & $4355.4^{* * *}$ & $3251.4^{* * *}$ \\
\hline ADF test & $-7.600^{* * *}$ & $-8.568^{* * *}$ & $-6.166^{* * *}$ & $-4.439^{* * *}$ & $-28.265^{* * *}$ & $-8.294^{* * *}$ & $-11.590^{* * *}$ & $-8.256^{* * *}$ & $-7.770^{* * *}$ & $-8.791^{* * *}$ \\
\hline
\end{tabular}

Note: J-B refers to the empirical statistics of the Jarque-Bera test for normality; Q (30) is the Ljung-Box statistic which tests a null hypothesis that autocorrelations up to lag 30 equal to zero. The Augmented Dickey-Fuller (ADF) tests a null hypothesis of a unit root in (non-stationarity of the series) the equation featuring a constant term. *,** and $* * *$ indicate the rejection of the null hypothesis of associated statistical tests at the $10 \%, 5 \%$ and $1 \%$ levels respectively. The number of observations is 2651 .

10 The S\&P GSCI Non-Energy Commodity index return is adopted to refer to the commodity market variable as this world-production weighted index may be used as a proxy of changes in economic conditions that affect commodity markets.

11 Corporate bond spread is viewed as a proxy of default risk and a strong predictor of stock market return (Fama and French, 1989) as it is the representative of the monetary compensation for holding risky assets.

12 The Euro Area 3-Month government bond yield is always regarded as a proxy of current economic conditions since it reflects the policy changes of the European Centre Bank.

${ }_{13}$ The Euro Area ten-year bond yield in the Euro area is used to reveal the relationship between market remuneration rates and the remaining time to maturity of long-term debt securities.

14 STOXX EUROPE 600 Index is a broad benchmark index tracking the company performances in 18 European countries.

15 Given a suggestion from a reviewer, we check the influence of likely sectoral variability in carbon exposure on our results. We replace the EUROSTOXX600 integrated index of all sectors with the EUROSTOXX600 integrated index of eight carbon intensive sectors, see Appendix B2 for further details and results. 
In summary, the continuously compounded returns of the eight assets (EUA, OIL, COAL, EPE, GAS, NCIR, ECRS, and ESTOXX) are computed as $\ln p_{t}-\ln p_{t-1}$, and these returns are found to be stationary. The continuous compounding returns of the two government bond assets (ELTB and ESTB) are found to be difference stationary (refer to Appendix A1 for more details on the variables examined, including source and transformations). Following previous studies (see, Khalifa et al., 2011; Zhang and Wang, 2014; Antonakakis and Kizys, 2015; Zheng et al., 2015), we adopt the absolute values of returns to calculate unconditional volatility. Forsberg and Ghysels (2007) show that absolute returns predict volatility well given: (i) excellent performance for population prediction, (ii) less sampling error, and (iii) being robust to jumps.

Table 1 provides the descriptive statistics of the daily returns and absolute returns (volatility). Panel A presents summary statistics of the ten assets returns with the average level from $-0.174 \%$ (for ESTB) to $0.01 \%$ (for ECRS). The unconditional volatility as measured by the standard deviation ranges from $0.20 \%$ (for ECRS) to $10.1 \%$ (for EPE). ECRS provides a very stable investment opportunity, reflected by the lowest standard deviation of $0.20 \%$. NCIR and ESTOXX are also relatively safe investments with low standard deviations of $1.0 \%$ and $1.3 \%$ respectively. As a young commodity market, EUA exhibits a negative return with relatively high volatility $(3.1 \%)$, which is also reflected by a wide return range of $67.6 \%$. The EPE is also a highly volatile asset with the widest range between the maximum and minimum daily returns of $173.4 \%$ and $-257.1 \%$. The electricity market has a greater downside risk as implied by the negative (positive) skewness which suggests a higher (lower) probability of large negative versus large positive price developments. According to Panel A, all assets are negatively skewed with the exception of GAS, ELTB and ECRS. Additionally, the excess kurtosis values (above three) indicate that all variables are leptokurtic, with a higher peak and a fatter tail than in a normal distribution, which is confirmed by the Jarque-Bera (JB) statistics, which strongly reject the null hypothesis of a normal distribution. The Ljung-Box test statistics prove the presence of temporal dependence in the returns (except for NCIR) because the statistic Q (30) does not support the null hypothesis of the white noise process. Finally, all return series are stationary under the Augmented Dickey-Fuller (ADF) test, with the null hypothesis of a unit root being rejected at the $1 \%$ level.

Panel B reports basic descriptive statistics of absolute returns (volatility). First, EPE has the highest mean absolute return (3.12\%), followed by ELTB (3.04\%). By contrast, ECRS has the lowest 
mean absolute return $(0.11 \%)$, and the sample standard deviation displays an analogous pattern $(0.1 \%)$. Along similar lines, the widest (narrowest) range of variation, calculated as the difference between the minimum and maximum absolute returns, is for EPE (ECRS). Absolute returns of all variables are positively skewed and leptokurtic: the former implies that more volatile episodes in these returns are more likely to occur than less volatile episodes, and the latter indicates that episodes of extreme volatility movements are more likely to occur within the heavy tails relative to a normal distribution. These results are consistent with the JB test. Additionally, the Q-statistics and ADF test show that all the absolute return series are serially correlated and stationary. To, at least partly, consider the serial correlation in the data; we include five lags of each variable in the VAR models.

\section{Empirical Results}

\subsection{Static connectedness analysis}

\subsubsection{Total static spillovers}

Based on a linear VAR model of order 5, and Lanne-Nyberg variance decomposition of 10-day ahead forecast errors ${ }^{16}$, we investigate the static total spillover index matrix of returns (Panel A) and volatilities (Panel B), respectively. A VAR (5) is estimated in the spillover index calculation to control for the week effects and adjust for the weekend effect, which makes Monday returns cover more time than the other days (Dubois and Louvet, 1996; Chang and Kim, 1988).

Specifically, in Table 2, the connectedness matrix can be further segregated in two: diagonal values and off-diagonal values. The diagonal elements reflect the variance arising due to "self", whereas the off-diagonal elements are the proportional contribution by other entities in the forecast error variance equation. The last column of Table 2, labeled "Directional from others" (coined as "FROM"), is equal to the row sum excluding the diagonal elements and provides the total directional spillovers from all others to market $i$ (recall Eq. (6)). The row at the bottom, labeled "Directional to others" (coined as "TO"), is equal to the column sum excluding the diagonal elements, and reports the total directional spillover from market $j$ to others (see Eq. (7)). The difference between the "TO" and "FROM" values of each variable gives its net spillover (coined as "NET") to/from other variables (see

\footnotetext{
16 To assess the sensitivity of results to the choice of parameters, we use alternative VAR orders, forecast horizon and a rolling window size. We find our results to be robust to these changes, and these additional results are available upon request.
} 
Eq. (8)), it identifies whether an asset is a net transmitter or net receiver of a shock in the system. The lower right corner reports the total spillover index (coined as "TOTAL", see Eq. (5)), that is, the average return (volatility) connectedness in the "Carbon-Energy-Finance" system. As the focus of this study is on the connectedness of EUA and OIL with other assets indicators, the values of the $1^{\text {st }}$ row (column) and the $4^{\text {th }}$ row (column) in Panels A and B are our primary focus.

According to the total return spillover index in Panel A of Table 2, an average of $42.26 \%$ of the return's forecast error variance is derived from other markets, which indicates that the return connectedness in the "Carbon-Energy-Finance" system is considerable. All in all, ESTOXX is the largest return transmitter in the system with the "NET" contribution of $34.51 \%$, followed by NCIR, OIL, and ELTB with net contributions of approximately 15\%. By contrast, the EPE is found to be the most dominant return receiver, closely followed by the ESTB and ECRS, with net return spillovers of $31.29 \%, 26.15 \%$ and $23.64 \%$, respectively. By comparison, the stock market, non-energy commodity market and oil market have important roles in the return connectedness process because they strongly contribute to the system and also receive much information from it. These results suggest that the return expectations of investors in the stock market, commodity markets and long-term bond markets tend to influence the expectations in the electricity, T-bill bond, corporate bond, natural gas, and carbon markets, leading to the observed linkages in the system.

On a pairwise basis, we concentrate on the performance of EUA and OIL, and their connectedness with other assets, especially with non-energy financial indicators. For EUA, the results in the $1^{\text {st }}$ row and column in Panel A indicate that EUA is a net return receiver that contributes to the FEVD of other variables on average by $39.31 \%$ but receives $40.61 \%$ spills from the other variables. For instance, the highest EUA return connection of approximately $8.39 \%$ is observed from COAL to EUA, closely followed by ESTOXX, OIL and GAS, which contribute 7.43\%, 6.78\%, and 6.2\% to EUA, respectively. By contrast, the influence of the carbon market on the fossil fuel markets is approximately $7.81 \%$ on GAS and $6.37 \%$ on COAL. These unsurprising findings provide further evidence of the close interactions among carbon, energy and stock, since the industrial production activities determined by the price of commodities and stock are the dominant sources of carbon emissions, and the carbon price tends to affect the gas and coal price by determining the fuel-switching behavior of producers. In terms of the specific linkages with non-energy financial assets, on the one hand, EUA and OIL connect with 
non-energy financial assets in a similar manner, that is, the return connectedness with commodity and equity markets are much more significant than that with bond markets. This finding is in line with the results of Koch (2014), where the shocks in the bond market have only a modest impact on the connectedness, which contrasts with stock market shocks. For instance, the contributions of bonds to EUA and OIL are quite fragile given the spillover intensities are less than 5\%; conversely, the contributions of the stock market to EUA and OIL reach nearly $8 \%$ and $13 \%$, respectively. Additionally, both EUA and OIL contribute more to bonds, which may be explained by the following: as commodity prices rise, this increases the cost of goods, putting pressure on inflation and potentially triggering monetary tightening. On the other hand, there are obvious differences between EUA and OIL, for example, (i) the return connectedness of OIL with both NCIR and ESTOXX is much stronger than that of EUA. For example, the contribution of NCIR (ESTOXX) to OIL (15.47\% and 12.91, respectively) is almost triple (double) of that to EUA (5.44\% and $7.43 \%$, respectively), and (ii) the return connectedness of OIL with NCIR and ESTOXX is more symmetric than that of EUA because EUA receives more from NCIR and ESTOXX but transmits less to these two markets. The stronger return linkages between OIL, NCIR, and ESTOXX are partly in line with the findings of Singh et al. (2019) and Wang and Wang (2019), which may be because of i) the substitution of fossil fuels with bio-fuel, ii) hedging strategies against inflation induced by high oil prices, and iii) the frequent portfolio diversification between oil and securities. The symmetrical feedback effects between EUA, NCIR, and ESTOXX suggest that the influence of the carbon market on the financial markets remains limited compared with that of OIL.

Panel B of Table 2, the volatility connectedness in the "Carbon-Energy-Finance" system is slightly weaker than the return connectedness (34.82\% compared with $42.26 \%$ ) but remains substantial. This discovery is robust and supported when (i) an alternative sample is used, (ii) a carbon-intensive stock index is added, and (iii) weekly data is used (see Appendix B1-B3). However, this finding differs from Ji et al. (2018), who demonstrate that information linkages and spillovers are much stronger in the volatility system than in the returns system. Our opposing results may be because we analyze the connectedness in the "Carbon-Energy-Finance" system rather than the "Carbon-Energy" system. Similar to the roles acted in return connectedness, ESTOXX is the largest volatility net transmitter (30.58\%), followed by NCIR and ELTB, with the net contributions reaching nearly $20 \%$. By contrast, 
ESTB is the largest volatility net receiver (36.01\%), followed by EPE and EUA, with the net receipts of $29.44 \%$ and $7.33 \%$, respectively. This result suggests that in the "Carbon-Energy-Finance" system, several financial markets including the stock, non-energy commodity, and long-term bond markets tend transmit investor sentiment, including fear, to other parts of the system through volatility spillovers, with several markets including the T-Bill, electricity, and carbon markets being particularly sensitive to these panic driven shocks. The net receiver roles of EUA and EPE are consistent with the results of Ji et al. (2018).

Upon closer inspection, both EUA and OIL do not exhibit a strong connection with other assets in terms of volatility as they do with returns. Additionally, the volatility connectedness of EUA and OIL are heterogeneous in nature; such that we can conclude (i) both EUA and OIL only have relative strong volatility connectedness with COAL, but the linkage of OIL-COAL is relatively stronger and symmetrical; and (ii) OIL has much a closer volatility connectedness to non-energy financial assets, especially with ESTOXX (11.77\%) and NCIR (8.6\%). This finding does not support Wei and Lin (2016) who demonstrate that the oil market affects the volatility of the carbon market and stock market but is not affected by them to a lesser degree, and (iii) both EUA and OIL exhibit quite weak volatility connectedness with bond markets. By comparison, OIL tends to have closer relationship with ESTB, whereas EUA has a closer linkage to ECRS. This finding suggests that the T-Bill bond market is quite sensitive to shocks in the oil market because of the inflation concern caused by oil price changes, but junk bond volatility is more sensitive to price changes in carbon market since carbon prices influence the profit capacity and cash flow of covered companies. 
Table 2 Static return and volatility connectedness matrix of "Carbon-Energy-Finance" system (Full Sample).

\begin{tabular}{|c|c|c|c|c|c|c|c|c|c|c|c|}
\hline Obs. $=2651$ & EUA & $\mathrm{EPE}$ & GAS & OIL & COAL & NCIR & ESTOXX & ECRS & ESTB & ELTB & $\begin{array}{l}\text { Directional } \\
\text { from Others }\end{array}$ \\
\hline \multicolumn{12}{|c|}{ Panel A: return connectedness $(\%)$} \\
\hline EUA & 59.39 & 0.32 & 6.20 & 6.78 & 8.39 & 5.44 & 7.43 & 0.50 & 0.71 & 4.84 & 40.61 \\
\hline EPE & 3.19 & 66.23 & 5.14 & 1.31 & 4.53 & 6.88 & 2.70 & 1.55 & 2.09 & 6.37 & 33.77 \\
\hline GAS & 7.81 & 0.26 & 59.67 & 6.56 & 17.56 & 1.50 & 4.42 & 0.64 & 0.31 & 1.27 & 40.33 \\
\hline OIL & 4.35 & 0.07 & 3.48 & 49.68 & 8.10 & 15.47 & 12.91 & 0.70 & 1.89 & 3.34 & 50.32 \\
\hline COAL & 6.37 & 0.27 & 12.17 & 9.69 & 55.17 & 2.91 & 8.38 & 1.14 & 2.80 & 1.10 & 44.83 \\
\hline NCIR & 4.36 & 0.30 & 0.95 & 15.83 & 1.95 & 52.24 & 16.31 & 1.76 & 2.29 & 4.02 & 47.76 \\
\hline ESTOXX & 4.66 & 0.26 & 2.27 & 12.13 & 5.64 & 14.76 & 45.01 & 2.60 & 1.87 & 10.81 & 54.99 \\
\hline ECRS & 2.47 & 0.37 & 2.22 & 4.61 & 1.30 & 6.28 & 12.70 & 64.06 & 1.16 & 4.83 & 35.94 \\
\hline ESTB & 3.24 & 0.30 & 3.52 & 3.27 & 4.13 & 5.70 & 10.41 & 2.53 & 58.32 & 8.58 & 41.68 \\
\hline ELTB & 2.86 & 0.32 & 1.24 & 4.36 & 0.90 & 5.11 & 14.25 & 0.88 & 2.41 & 67.66 & 32.34 \\
\hline Directional to others & 39.31 & 2.48 & 37.18 & 64.55 & 52.51 & 64.06 & 89.51 & 12.31 & 15.53 & 45.16 & \\
\hline Net spillovers & -1.30 & -31.29 & -3.15 & 14.23 & 7.68 & 16.30 & 34.51 & -23.64 & -26.15 & 12.82 & 42.26 \\
\hline \multicolumn{12}{|c|}{ Panel B: volatility connectedness $(\%)$} \\
\hline EUA & 78.02 & 0.63 & 1.71 & 1.09 & 6.28 & 2.91 & 5.31 & 2.98 & 0.22 & 0.85 & 21.98 \\
\hline EPE & 2.77 & 66.05 & 5.34 & 2.71 & 3.16 & 3.70 & 5.04 & 3.17 & 0.86 & 7.21 & 33.95 \\
\hline GAS & 2.30 & 1.01 & 70.69 & 3.89 & 9.55 & 3.71 & 1.92 & 4.77 & 0.33 & 1.82 & 29.31 \\
\hline OIL & 0.56 & 0.44 & 0.99 & 64.20 & 8.24 & 8.60 & 11.77 & 1.82 & 1.29 & 2.10 & 35.80 \\
\hline COAL & 2.15 & 0.19 & 5.20 & 9.86 & 65.84 & 5.11 & 6.04 & 1.94 & 2.89 & 0.78 & 34.16 \\
\hline NCIR & 1.41 & 0.65 & 1.55 & 7.33 & 4.43 & 63.69 & 13.41 & 0.73 & 2.73 & 4.08 & 36.31 \\
\hline ESTOXX & 2.70 & 0.30 & 1.28 & 7.94 & 4.10 & 12.69 & 56.07 & 1.04 & 3.85 & 10.02 & 43.93 \\
\hline ECRS & 2.00 & 0.50 & 2.68 & 1.01 & 1.11 & 2.55 & 5.89 & 67.92 & 0.64 & 15.71 & 32.08 \\
\hline ESTB & 0.26 & 0.44 & 5.70 & 5.44 & 6.57 & 12.40 & 13.75 & 1.12 & 49.41 & 4.91 & 50.59 \\
\hline ELTB & 0.50 & 0.36 & 0.69 & 1.40 & 1.09 & 3.65 & 11.38 & 9.25 & 1.77 & 69.93 & 30.07 \\
\hline Directional to others & 14.65 & 4.51 & 25.15 & 40.65 & 44.52 & 55.32 & 74.51 & 26.81 & 14.57 & 47.49 & \multirow{2}{*}{34.82} \\
\hline Net spillovers & -7.33 & -29.44 & -4.16 & 4.85 & 10.36 & 19.02 & 30.58 & -5.27 & -36.01 & 17.41 & \\
\hline
\end{tabular}

Note: The results in this table are based on 2651 daily observations ranging from 3/4/2008 to 7/17/2018 (excluding the Phase I of EU ETS). The inner matrix represents pairwise spillover. The light blue shaded region represents system-wide "FROM" and "TO" spillover. The deep blue shaded region represents system-wide "NET" spillover. The green shaded region exhibits the pairwise spillover between EUA and financial assets, while the orange shaded region displays the pairwise spillover between OIL and financial assets. The extreme right bottom corner value of the matrix is the system-wide "TOTAL" spillover. 


\subsubsection{Structural breaks and network connectedness}

As mentioned in Section 4, our sample period covers various important events. Thus, we examine if any formal structural breaks can be detected and if the connectedness of EUA with other indicators has been influenced by these breaks. To do this, we first adopt the ICSS algorithm of Inclan and Tiao (1994) to test multiple breaks in the unconditional variance of EUA. Next, the full sample is divided into several subsamples based on the break date. Finally, both return and volatility connectedness during each sub-sample period is exhibited through network diagrams.

According to the ICSS test, the dates of three structural breaks are $6 / 24 / 2009,6 / 3 / 2010$, and 3/2/2017. The first break could be attributed to the European Parliament elections ${ }^{17}$ and the announcement and actions regarding the European Economic Recovery Plan ${ }^{18}$. This result is in line with Koch (2014), who uncovers that both correlations of carbon-stock and carbon-bonds correspond to the turbulent periods' peak around the Lehman Brothers failure and then persist until around mid2009. The second break may be attributed to the General election in the United Kingdom ${ }^{19}$ and the deterioration of the Eurozone crisis ${ }^{20}$, which also corresponds to Koch (2014), That is, the European sovereign debt crisis in 2010, which affected, among others, Greece and Ireland, has a crucial impact on market linkages with more negative carbon-bonds and more positive carbon-stock correlations. Finally, the third break could be generated by OPEC production cut agreement ${ }^{21}$ and the EU ETS reformation agreement ${ }^{22}$ for Phase IV of the EU ETS.

On the basis of the three structural breaks, the whole sample is divided into four sub-samples with the observations of 333 (subsample I), 242 (subsample II), 1727 (subsample III), and 349 (subsample IV), respectively. Following Lundgren et al. (2018), we exhibit the network plot of system-wide return connectedness (see Fig. 1) and volatility connectedness (see Fig. 2) during each sub-sample period,

\footnotetext{
17 European Parliament Elections, the biggest trans-national elections in history, were held in the 27-member states of the European Union between June 4 and 7, 2009.

18 For example, at the G20 London Summit in April 2009, Europe's leaders announced that they would take measures to address the economic crisis and reform the global financial system.

19 The 2010 United Kingdom general election was held on May 6, 2010.

20 In April 2010, Greek borrowing costs reach yet further record highs. The EU announces that the Greek deficit is even worse than thought after reviewing its accounts $-13.8 \%$ of GDP, not $12.7 \%$.

21 OPEC announced an agreement whereby 11 of the then-active 13 members would reduce crude oil production by approximately 1.2 million barrels per day (bpd) for 6 months starting January 1, 2017.

22 On February 28, 2017, the Environment Council adopted a general approach on the ETS reform. It would maintain the higher intake rate for the MSR (Market Stability Reserve) until the end of 2023, one year longer than proposed by Parliament.
} 
respectively. In Figs. 1-2, each asset indicator is represented as a node. Notably, the red (green) color of a node illustrates the net transmitter (recipient) of spillovers (i.e., the difference between "TO" and "FROM"). The edge size shows the magnitude of the pairwise spillovers, which is also reflected in the edge color (yellow [weak]), red and purple [medium], and blue [strong]). In this section, due to the space restrictions, we focus on the influence of each break on the connectedness of EUA, namely, the carbon-finance linkages.
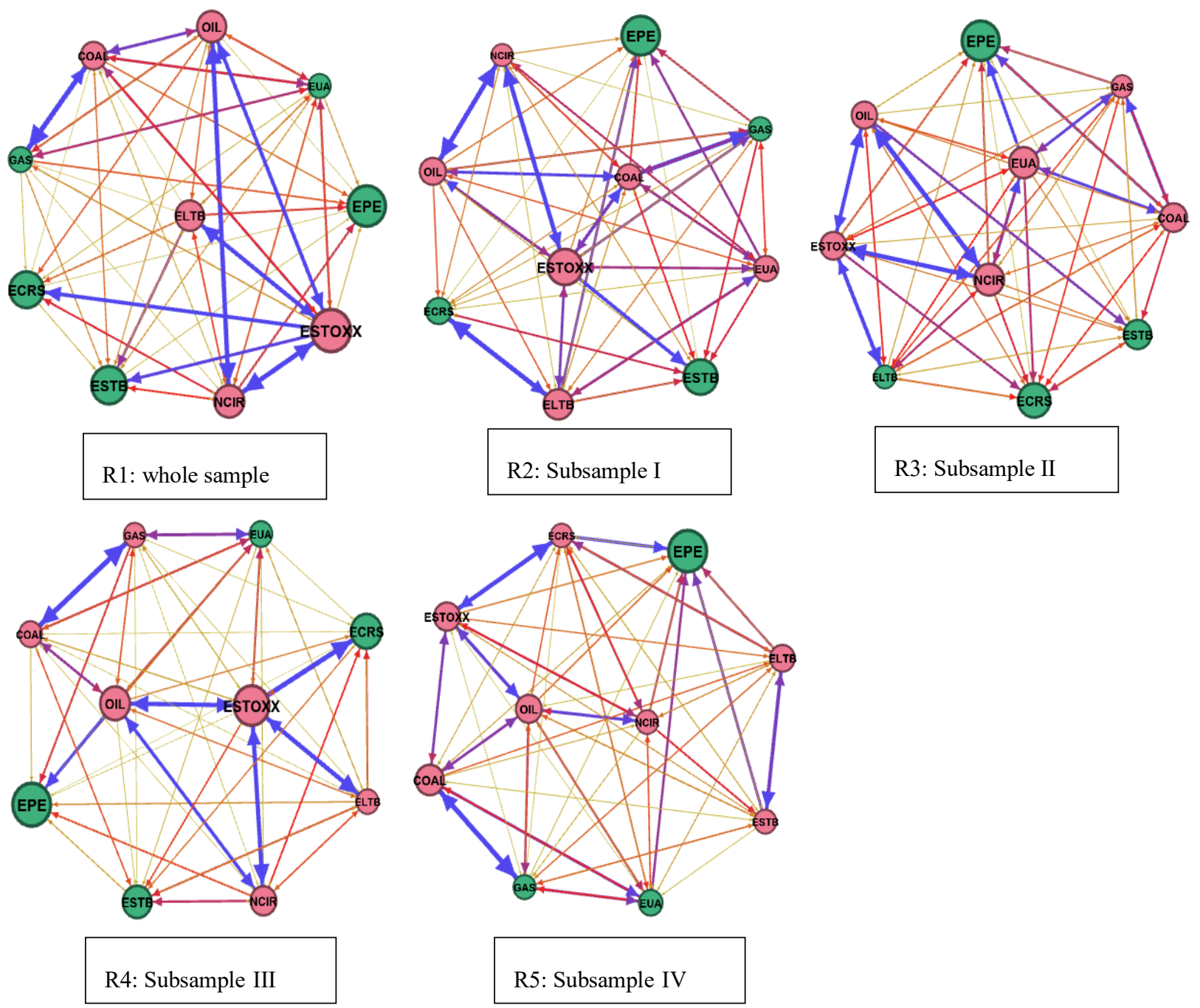

R5: Subsample IV

Fig. 1. Network Diagrams of the Bidirectional Return Connectedness.

Note: R1-5 refers to the return connectedness in the full sample and the four subsamples respectively. A node's red (green) color indicates the net return spillover transmitter (recipient). The size of the node shows the total magnitude of the net-pairwise directional spillover. The magnitude is also depicted by both the color of the edge (yellow [weak], red, and purple [medium], or blue [strong]) and the thickness degree of edge (thin [weak], or thick [strong]). 

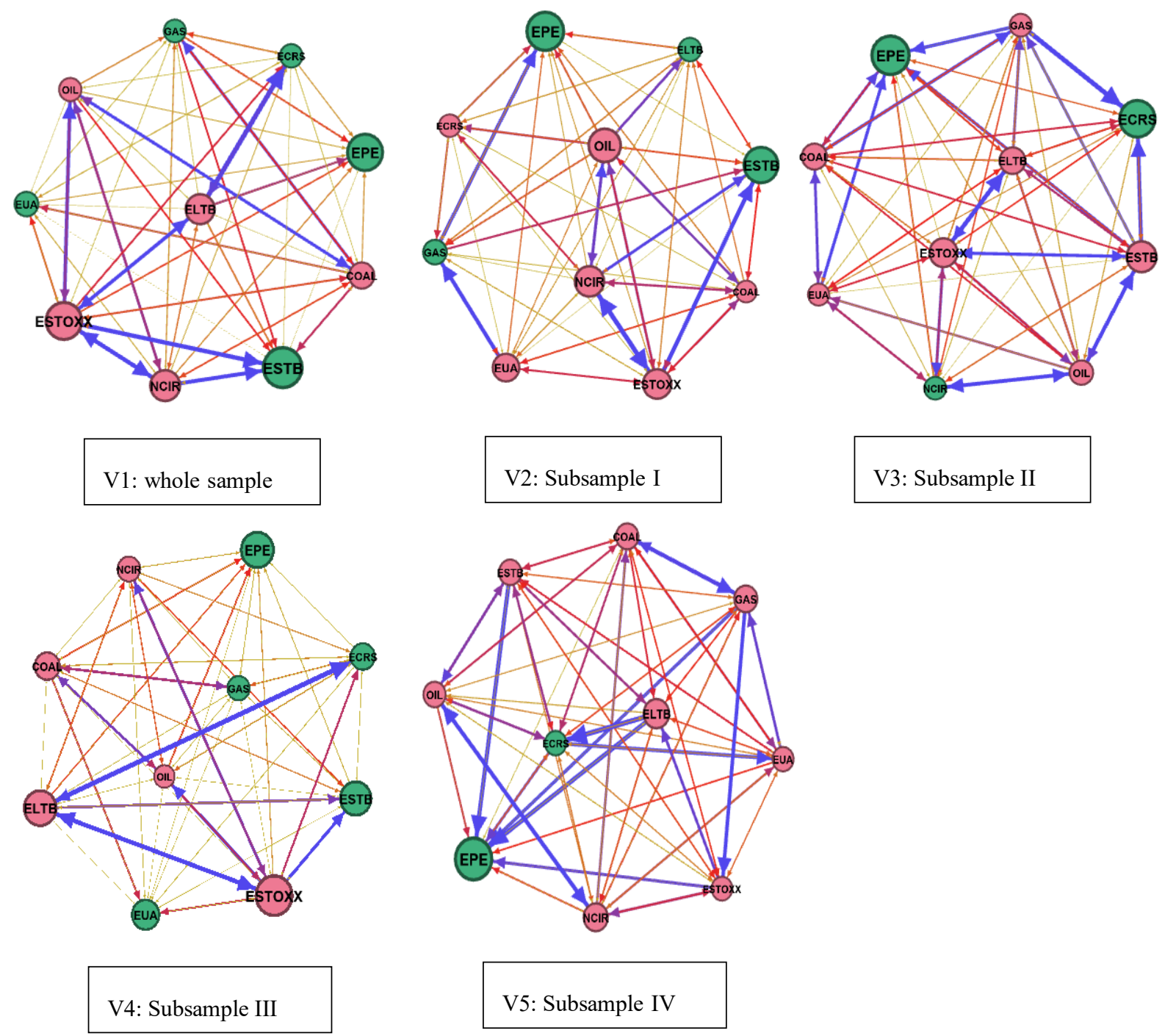

V3: Subsample II

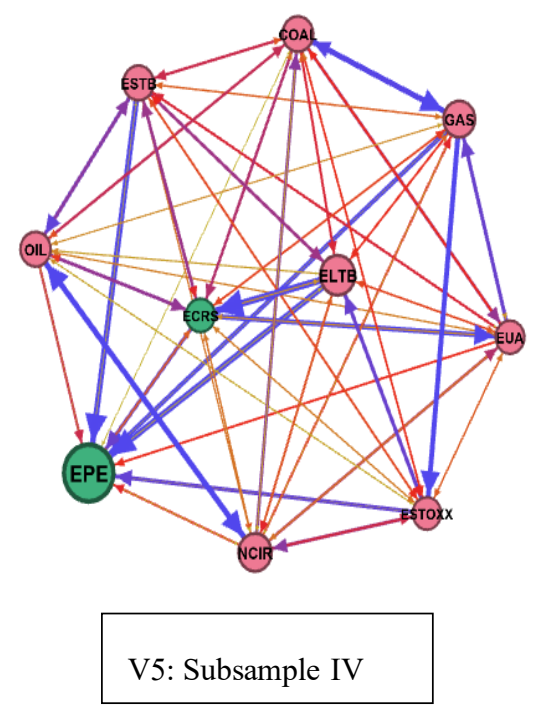

Fig.2. Network Diagrams of the Bidirectional Volatility Connectedness.

Note: V1-5 refers to the volatility connectedness in the full sample and the four subsamples respectively. A node's red (green) color indicates the net volatility spillover transmitter (recipient). The size of the node shows the total magnitude of the net-pairwise directional spillover. The magnitude is also depicted by both the color of the edge (yellow [weak], red, and purple [medium], or blue [strong]) and the thickness degree of edge (thin [weak], or thick [strong]).

Overall, in Figs.1-2, the structural breaks (especially the second) are significant because the network connectedness for the whole sample is different from that for the subsamples. Fig. 1 displays the significant influence of the second break on the system-wide return connectedness because many thin edges with a light color appear during subsamples III and IV. For the general response of EUA, the nodes show that (i) the net contribution of EUA in the system increased after the first structural break in 2009, and (ii) EUA switches from "Net return transmitter" to "Net return receiver" after the second break in 2010. Additionally, the edges between EUA and other assets in the subsamples demonstrate that (i) the return interactions between EUA and non-energy financial assets are strong in 
subsample I, (ii) carbon-finance linkages decrease but carbon-energy linkages increase in subsample II, (iii) the return connectedness of EUA with financial assets, plunges in subsample III, and (iv) carbon-energy linkages increase a little in subsample IV. Furthermore, the changes in color and thickness of each edge between EUA and non-energy financial assets reveal that (i) EUA connects closely with almost all non-energy financial assets except ECRS in subsample I (i.e., the great recession period ${ }^{23}$ ); (ii) the connectedness of EUA with NCIR and ECRS increase but the linkages with ESTOXX, ESTB and ELTB decrease in subsample II (i.e., period of economy recovery); (iii) the interactions between EUA and all financial assets plunge significantly in subsample III (i.e., period of uncertainty ${ }^{24}$ ); and (iv) the interactions between EUA, ECRS, and NCIR rise in subsample IV (i.e., period of economic growth).

Fig. 2 depicts that the volatility spillovers are more sensitive to the shocks than return spillovers. Initially, the role of EUA in the system is transferred from the "Net volatility transmitter" to "Net volatility receiver" after the second break in 2010 , and then moves back to a "Net volatility transmitter" after the third break. Additionally, the net contribution of EUA to the system alters continually during different periods. The general changes in the edges demonstrate that (i) the volatility of carbon-energy linkages are stronger than that of carbon and finance in subsample I, (ii) the volatility of carbon-finance linkages increases in subsample II, (iii) the volatility of interactions between EUA and all other assets plunge after the second break, and (iv) the third break increases the volatility connectedness of EUA with all other assets significantly. Finally, the edges between EUA and financial assets show that (i) during subsample I, EUA interacts with ESTOXX, NCIR, and ELTB closely; (ii) the volatility connectedness with NCIR and ELTB increase after the first break; (iii) the volatility connectedness with all financial assets drops after the second break; and (iv) the interactions between EUA and almost all financial assets (except ESTOXX) increase significantly after the third break.

Overall, the aforementioned differences between the four sub-samples give rise to several notable findings. Specifically, EUA tends to connect with both energy and financial assets during recessions,

\footnotetext{
${ }^{23}$ The great recession is a term that represents the sharp decline in economic activity during the late 2000s. This term applied to both the US recession, officially from December 2007 to June 2009, and the ensuing global recession in 2009.

24 This period is filled with uncertain events, e.g., the 2010 general election in the United Kingdom; the evolution of the Eurozone crisis from 2010 to 2013; the effects of the end of quantitative easing in the United States in 2014; the Libya oil crisis in 2014; the Great fall of China from June 2015 to June 2016; Brexit in June 2016; and many reforming discussions in the EU ETS.
} 
which may be caused by contagion effects during the great recession period. This finding partly aligns with Koch (2014), that is, the degree of carbon-finance linkages heavily depends on market conditions and is exacerbated during times of crisis. Furthermore, during periods of economic recovery, the connectedness of EUA with energy assets and some financial assets (e.g., ECRS and NCIR) tends to increase, but the connection with ESTOXX tends to decrease. This finding may be explained by the following: during the recovery period, production activities increase such that the price linkages among the carbon price, energy prices, the financing environment and the profits of enterprises tighten. However, simultaneously, increases in the stock market could be observed which are driven by speculative investing rather than changes in the true investment potential of enterprises. Interestingly, both the volatility and return connectedness of EUA with almost all assets in the "Carbon-EnergyFinance" system tend to plunge during the period of uncertainty. One reason for this observation may be the frequent reforming of the EU ETS due to the oversupply of carbon allowances. Another reason could be that during times of heightened uncertainty, it is more difficult for investors to form expectations of future returns and potential spillovers, resulting in possible non-rational investment behavior.

\subsection{Dynamic Connectedness Analysis}

\subsubsection{Dynamic total spillovers}

To further capture the time-varying dynamics of the "TOTAL" connectedness and "NET" connectedness of EUA and OIL with other assets, we plot the system-wide connectedness, rolling over a window of 200 trading days ${ }^{25}$. To show the dynamic connectedness of EUA and OIL with all other assets and financial assets, the total interactions between (i) EUA, Energy and the financial assets, and (ii) EUA, OIL, and the financial assets are illustrated in Figs. 3 and 4, respectively. Notably, Panels A and B plot the dynamic total spillovers with respect to return and volatility separately, and the Centre for Economic Policy Research Euro Area Business Cycle indicator is used to identify recessions and capture the behavior of the spillover index over the business cycle. We cannot capture all the structural breaks in the system, as we did in Section 5.1 for EUA; however, the rolling window approach allows

\footnotetext{
${ }^{25}$ Following Inoue, Jin, and Rossi (2014), we choose the optimal window size that minimizes the conditional mean square forecast errors. This procedure is found to perform well under various types of structural changes.
} 
for evolution and (gradual) structural change in the "Carbon-Energy-Finance" system.
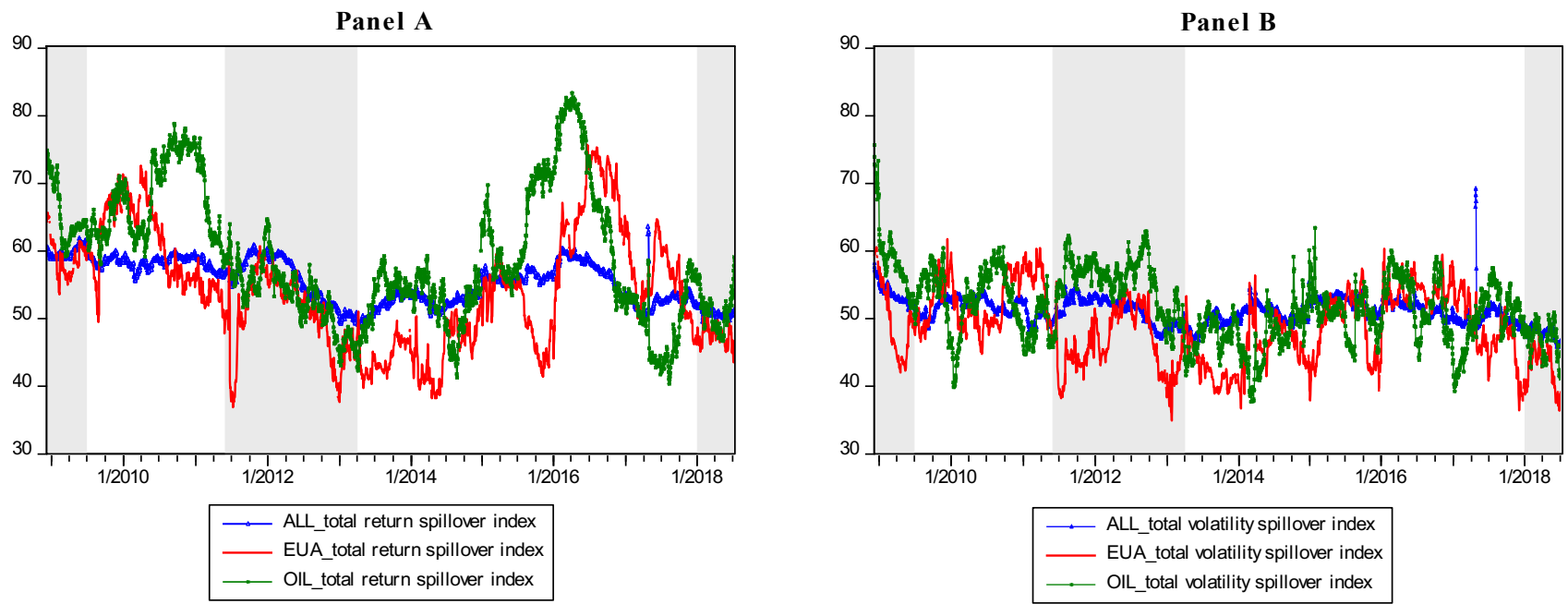

Fig.3. Rolling "TOTAL" returns and volatility connectedness with all assets

Note: Based on the Lanne-Nyberg variance decomposition method, several dynamic total spillover indices are calculated by reestimating the daily VAR (5), using a 200-day rolling estimation window with 10-day forecast horizon. Shaded areas represent CEPR Euro Area recessions. Panel A is generated from the return spillovers among EUA, Energy and financial assets, while Panel B refers to the volatility spillovers among EUA, Energy and financial assets. "ALL total return (volatility) spillover index" (overall average level) is the aggregate of every return (volatility) spillover index in the "Carbon-Energy-Financial" system; "EUA total return (volatility) spillover index" denotes the return (volatility) spillover only between EUA and all other assets in the "Carbon-Energy-Finance" system, while "OIL total return (volatility) spillover index" refers to the return (volatility) spillover only between OIL and all other assets in the "Carbon-Energy-Finance" system.

In summary, according to the four types of total spillover indices (blue lines) in Figs. 3 and 4, the overall average levels of volatility spillovers in the system are a little weaker than that of return spillovers, which correspond to the static results in Section 5.1. Additionally, a similar tendency is observed between the volatility and return connectedness, but the return spillovers are more volatile than the volatility spillovers especially from 2015 to 2017 . Additionally, EUA and OIL link with the non-energy financial indicators with smaller magnitudes than the average levels with all assets, but the average level does exhibit a more stable dynamic, especially from 2008 to 2013. In summary, our results support the existence of a relative strong link between the carbon and financial markets, as also seen in Koch (2014), which is in stark contrast with Chevallier (2009), Daskalakis et al. (2009), and Hintermann (2010) who document market segmentation. 

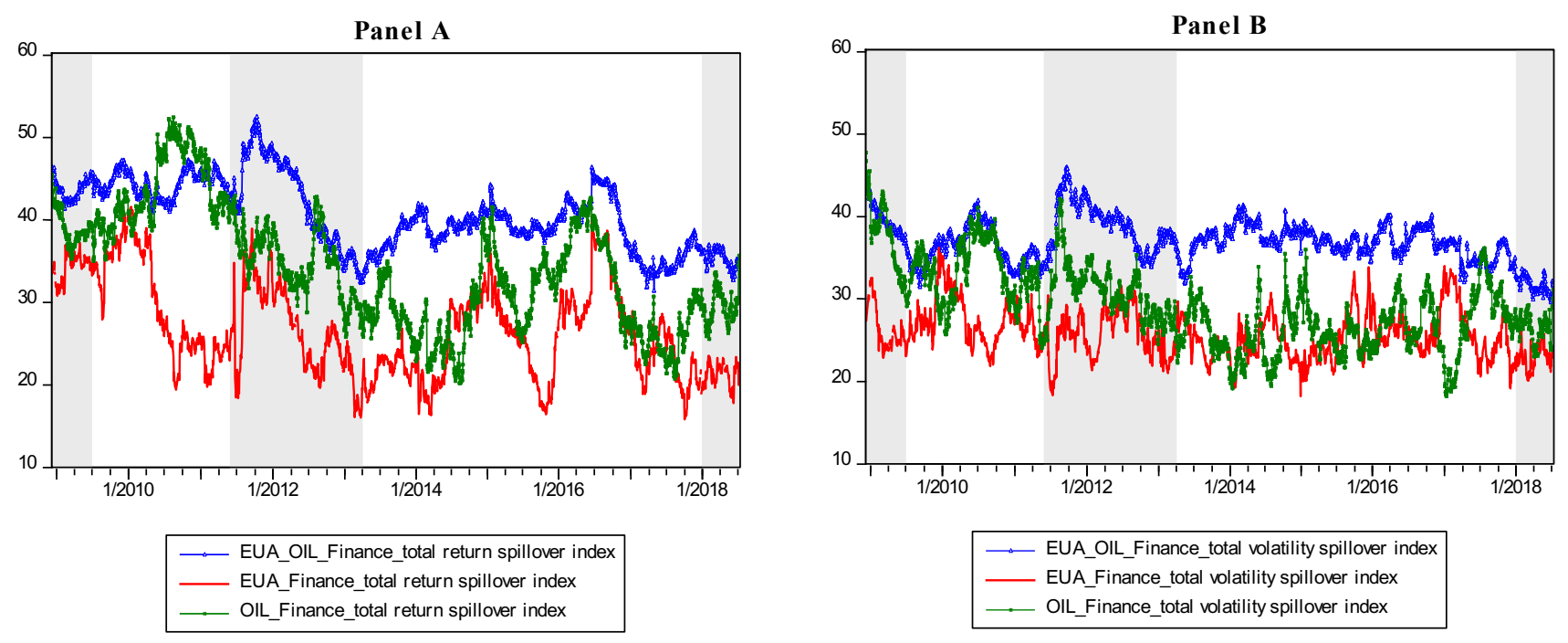

Fig.4. Rolling "TOTAL" returns and volatility connectedness with financial assets

Note: Based on the Lanne-Nyberg variance decomposition method, several dynamic total spillovers are calculated by re-estimating the daily VAR (5), using a 200-day rolling estimation window with 10-day forecast horizon. Shaded areas represent CEPR Euro Area recessions. Panel A is generated from the return spillovers among EUA, OIL and financial assets, while Panel B refers to the volatility spillovers among EUA, OIL and financial assets. "EUA OIL Finance total return (volatility) spillover index" (financial overall average level) denotes the return (volatility) spillovers between all pairs that only include EUA, OIL and financial assets. "EUA_finance total return (volatility) spillover index" represents the return (volatility) spillovers only between EUA and financial assets. Likewise, "OIL_finance_total return (volatility) spillover index" considers the return (volatility) spillovers only between OIL and financial assets.

Inspecting EUA and OIL, we observe the following, first, despite showing similar cyclical movements to EUA, OIL tends to connect with the system more strongly than the average level (blue lines in Fig. 3). Second, the connectedness of EUA and OIL with financial assets is smaller than the financial average level of the system (blue lines in Fig. 4). Third, return connectedness of both EUA and OIL fluctuate more than their volatility connectedness. Fourth, the connectedness of OIL and EUA are more variable than the overall average level, particularly from 2010 to 2012 and 2015 to 2018 . Finally, dynamic return spillovers exhibit much higher connectivity in 2012, 2014, 2015 and 2016, which may be attributed to some extreme financial events as mentioned in Wang and Guo (2018).

As for the dynamics of the return spillovers, Panel A in Fig. 3 shows that (i) due to the global financial crisis, both the connectedness of EUA and OIL plunge from their high pre-2009 levels of $65 \%$ and $75 \%$, respectively; (ii) due to stimulation from a series of economy recovery plans, the return spillovers of EUA and OIL peak in the first quarter of 2010 and 2011, respectively, with values exceeding 70\%; and (iii) during the high uncertainty period (2011-2017), the return connectedness of EUA and OIL experience extraordinary co-movement and volatility that peaks in 2016 with values over $70 \%$ and $80 \%$, respectively. We make two noteworthy observations during this period, first, the return connectedness of EUA and OIL steadily drops rather than rapidly rising during the recession 
period, which suggests that the slowing economic conditions and illiquidity in the financial markets during recessions tend to reduce the return connectedness between markets. Second, fluctuations in return connectedness tend to be linked to key economics and financial events, because the nature and behavior of the connectedness with financial assets (see Panel A in Fig. 4) are nearly same as those with all assets (see Panel A in Fig. 3). For example, the increase in 2013 may be due to the Eurozone crisis; the jump in 2014 may be due to economic uncertainty in the US and the Libya oil crisis; and the dramatic rise between 2015 and 2016 may be attributed to the great fall of China ${ }^{26}$, the slowdown of Chinese economy ${ }^{27}$ and Brexit.

By comparison, the volatility connectedness in Panel B of Figs. 3 and 4 display distinctively different patterns to return connectedness. First, a more dramatic drop in volatility spillovers occurs during the recession period before mid-2009. A possible explanation for this phenomenon is the market reaction to the crisis was drastic but transitory. Second, more persistent high-level volatility interactions exist during the recession period (from mid-2011 to 2013), which highlights the contagion effects of the recession period are substantial. Third, the volatility spillovers fluctuate less than the return spillovers from 2015 to 2017, possibly suggesting that the return spillover effect is more sensitive to the prospects of a slowdown of the Chinese economy, Brexit and interest rate increases in the US. Finally, there is a big gap between the OIL-finance and EUA-finance linkages before 2013, but this gap shrinks thereafter, suggesting EUA and OIL have increasingly similar volatility connectivity with financial assets.

\subsubsection{Dynamic net spillovers}

We now examine the time-varying directional spillovers by decomposing the total spillover index (Section 5.2.1) into two directional components. First, we identify the net roles of the carbon and oil markets (Fig. 5) from the difference between the "TO" and "FROM" spillovers (recall Eq. (7) and (6)). A positive (negative) value indicates that this market is a net transmitter (receiver) of return and volatility spillovers to others (recall Eq. (8)). Next, we further investigate the net pairwise return (see Fig. 6) and volatility (see Fig. 7) spillovers (recall Eq. (9)) between EUA and all other assets, and

\footnotetext{
26 The Chinese stock market turbulence began with the popping of the stock market bubble in June 2015 and ended in early February 2016. A third of the value of A-shares on the Shanghai Stock Exchange was lost within one month of the event.

27 In 2015, the Chinese economy slowed to $6.9 \%$, the weakest observed in 25 years, due to the shift from a traditional manufacturing investment-export led model to a new services and consumption driven economy.
} 
compare the EUA-finance linkage with OIL-finance linkage in detail.
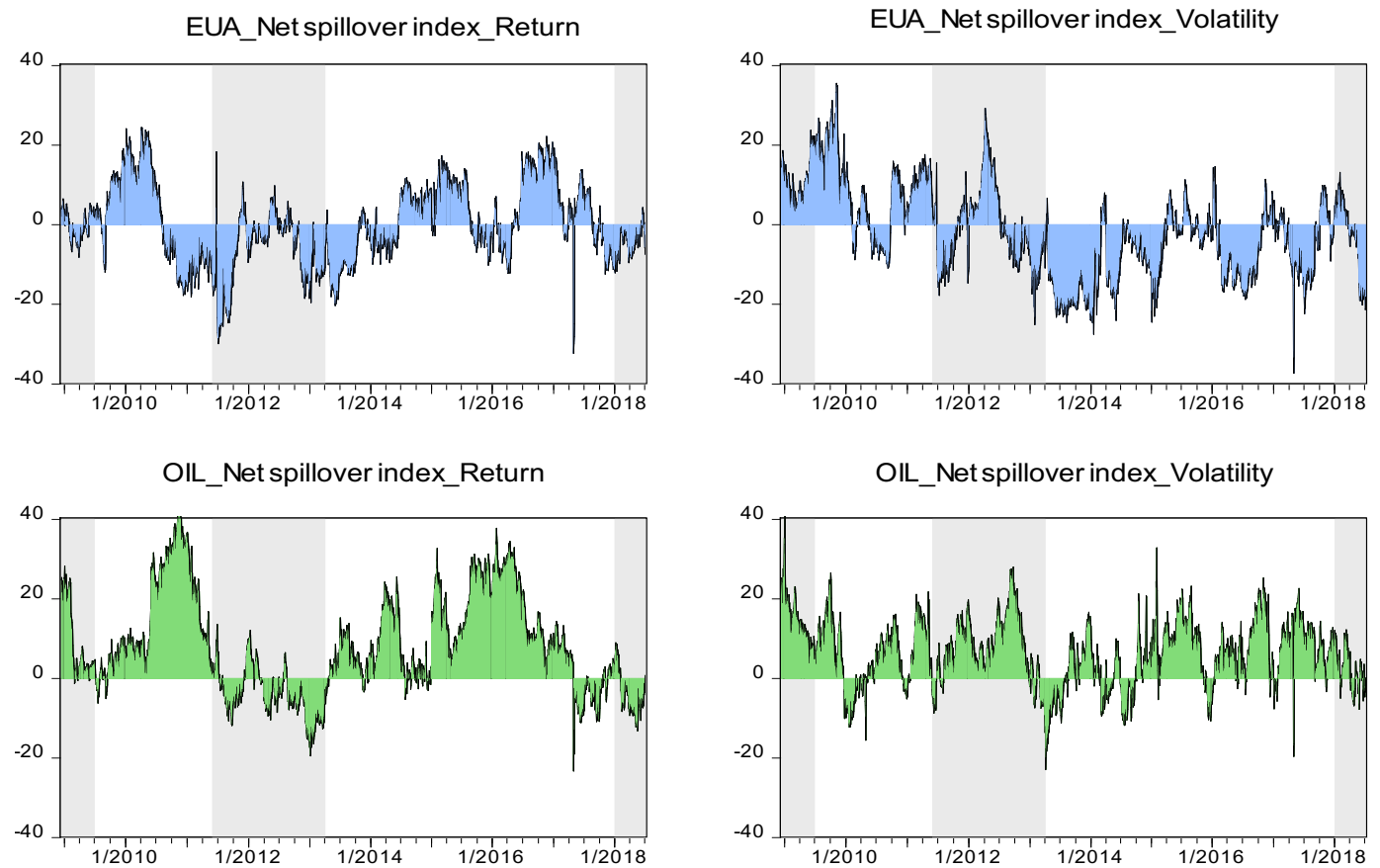

Fig.5. Rolling "NET" return and volatility spillovers of EUA and OIL

Note: The net returns (volatility) spillover index is the difference between the returns (volatility) transmitted from one market to others and the returns (volatility) received by that market from others. Positive (negative) value indicates that the variable is a net transmitter (receiver) of spillovers. The net return (volatility) spillover indices of EUA and OIL are exhibited using the blue and green area respectively. Shading area denotes Euro Area economic recessions as defined by the CEPR.

From Fig. 5, we can see that OIL acts as a net return and volatility transmitter in the "CarbonEnergy-Finance" system with a positive net spillover index during almost all the sample period. By contrast, as an emerging commodity, EUA acts as a net volatility receiver in the system because it receives more but contributes less during a large part of the sample period (2013-2018). However, the return role of EUA during the whole period is unclear. Further, although OIL generally plays a distinct role compared to EUA, there are still similar features during some specific periods. Specifically, both EUA and OIL tend to be return receivers during recessions with negative net spillover index values, but EUA is more sensitive to the shock to the system as indicated by its longer and stronger response as a net receiver. Both EUA and OIL tend to be net return transmitters during expansionary periods, but OIL contributes more than EUA to the system. Additionally, in terms of volatility connectedness, both EUA and OIL tend to be net transmitters before 2013, but EUA becomes a net receiver in almost all cases thereafter.

Figs. 6 and 7 illustrate the specific return and volatility net pairwise spillovers between EUA and other assets, and compare the EUA-finance and OIL-finance linkages. Overall, we observe that EUA 
links with each member dynamically since the net spillover index fluctuating within $-10 \%$ and $10 \%$. Specifically, Fig. 6 shows that EUA acts as a net receiver and a net transmitter for COAL and EPE, respectively. This suggests that the carbon return is more sensitive to spillovers from the coal return as coal is the most dominant source of carbon emissions, while electricity return responds to the change of carbon return significantly since carbon price is an important determinant of the production costs of power companies (Keppler and Mansanet-Bataller, 2010). Moreover, EUA tends to be a net receiver of OIL during the whole sample period, especially from 2010 to 2012 and 2015 to 2017 but contributes more to OIL from 2014 to 2015 . As for the connectivity with GAS, we are surprised that the general role of EUA is unclear during the whole sample; this implies that the feedback influence of EUA on GAS is stronger than on COAL. These findings corroborate previous findings on the connectedness patterns between EUA and energy asset, see Ji et al. (2018).

Additionally, from Fig. 6, we observe that OIL and EUA connect with non-energy financial assets in a similar fashion; however, the connectivity of OIL is stronger than that of EUA. To be more specific, both EUA and OIL act as net transmitters of ESTB but act as net receivers of ESTOXX and ELTB during the whole sample. This interaction between EUA, OIL and ESTB may be attributed to the influence of inflation on the T-Bill rates through both monetary policy and the investment behavior of investors, because the central bank tends to target the money supply based on inflation and investors are reluctant to purchase Treasuries when the yield on their investments does not keep up with inflation, making the investment a net loss in terms of real purchasing power. In addition, the connectivity of EUA and OIL with ESTOXX and ELTB may be explained by the following: the stock and long-term bond markets can predict the direction in which a country's economy is heading by observing strong indicators of investor confidence in the economy and government. Notably, EUA and OIL connect with NCIR and ECRS with an unclear role during the whole sample period, but they tend to be net receivers during recessions. These findings imply that NCIR and ECRS are inclined to be return triggers for both EUA and OIL in recessions. 


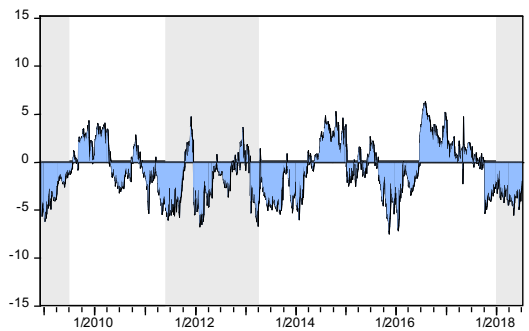

EUA_EPE

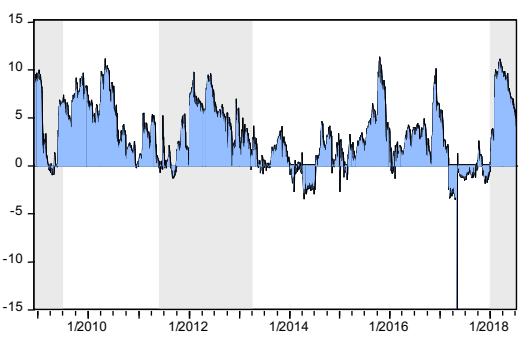

EUA ESTB / OIL ESTB

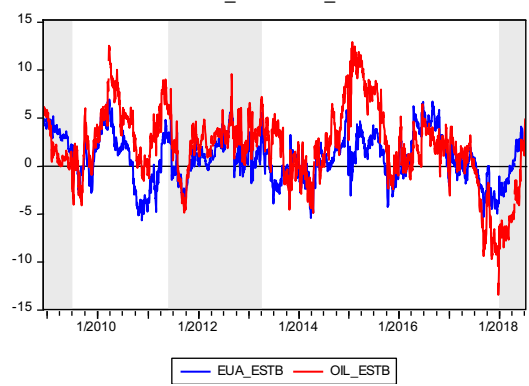

EUA GAS

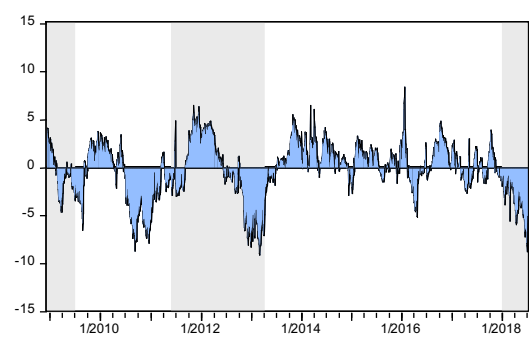

EUA_NCIR/OIL_NCIR

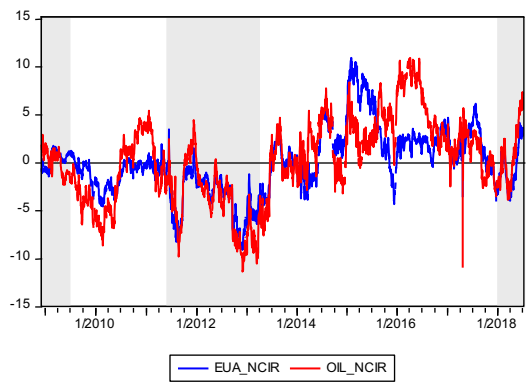

EUA_ECRS / OL_ECRS

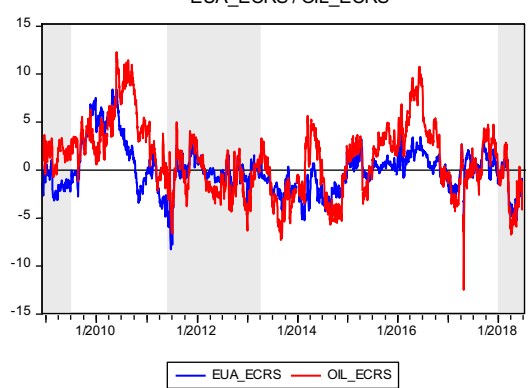

EUA_OIL

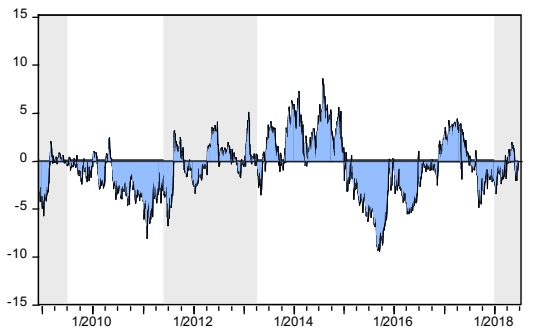

EUA_ESTOXX/OIL_ESTOXX

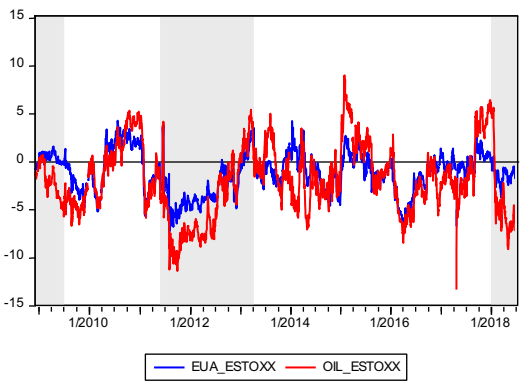

EUA_ELTB/OIL_ELTB

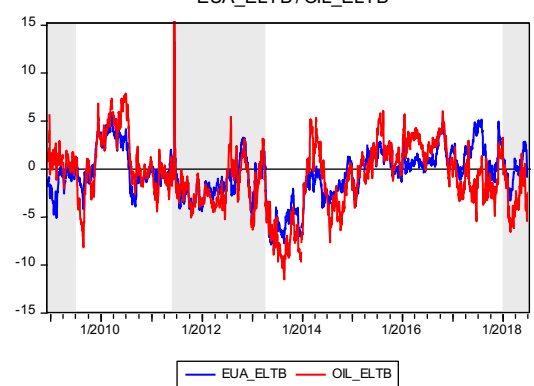

Fig.6. Rolling "NET PAIRWISE" return spillovers of EUA and OIL

Note: The net pairwise return spillover index is the difference between the return transmitted from one market to another and the return received by that one market from the other. Hence the positive values imply that the first market transmits more returns information to the second, whereas the negative values mean that the second markets send more returns information to the first one. The blue area represents the net pairwise return spillovers between EUA and each energy asset, while the blue and red lines depict the net pairwise return spillovers of EUA and OIL with non-energy financial assets respectively. Shaded areas denote EU economic recessions as defined by the CEPR. 
EUA_COAL

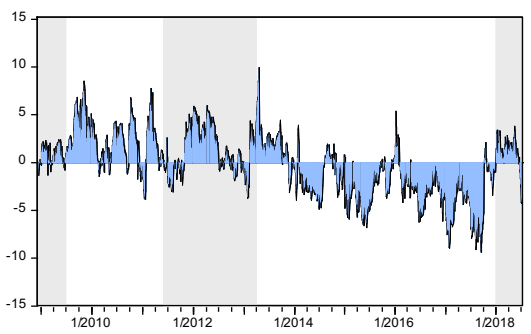

EUA_EPE

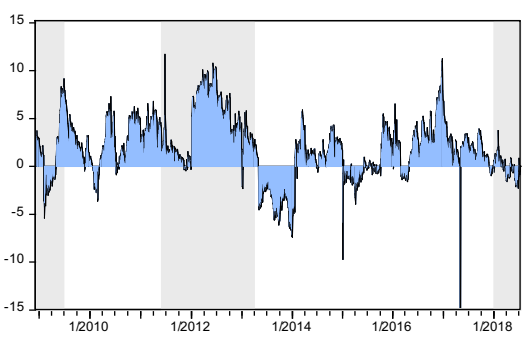

EUA_ESTB/OIL_ESTB

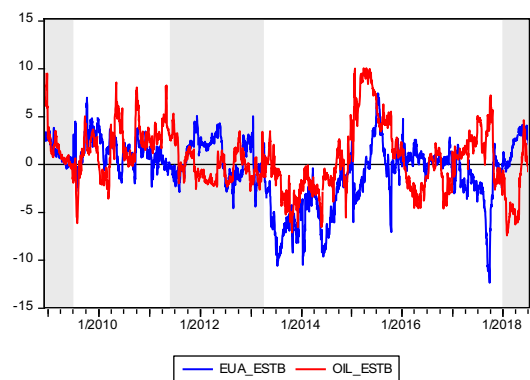

EUA_GAS

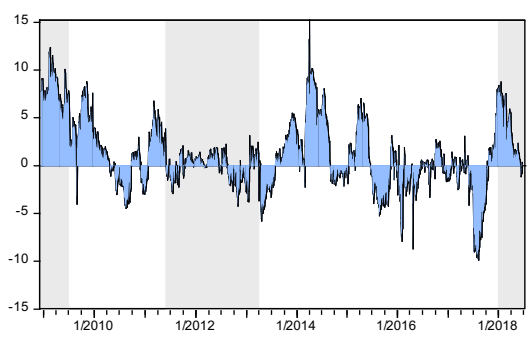

EUA_NCIR/OIL_NCIR

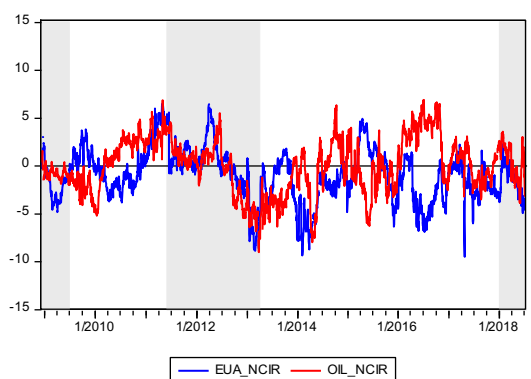

EUA_ECRS / OIL_ECRS

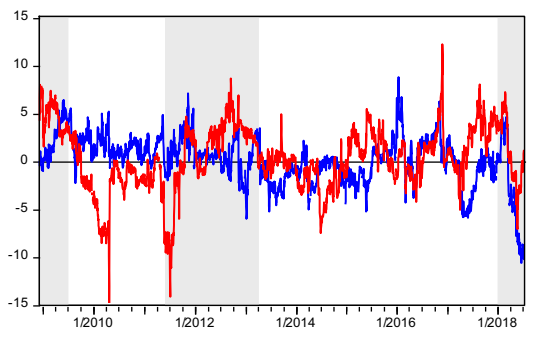

- EUA_ECRS - OIL_ECRS
EUA_OIL

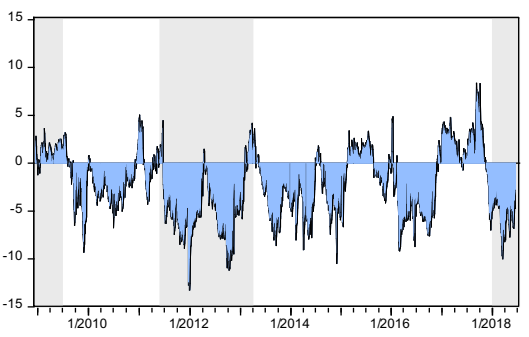

EUA_ESTOXX/OIL_ESTOXX

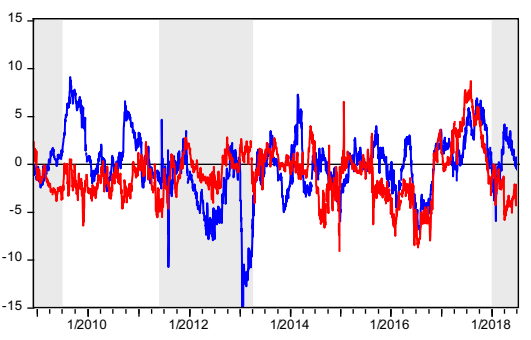

— EUA_ESTOXX — OIL_ESTOXX

EUA_ELTB/OIL_ELTB

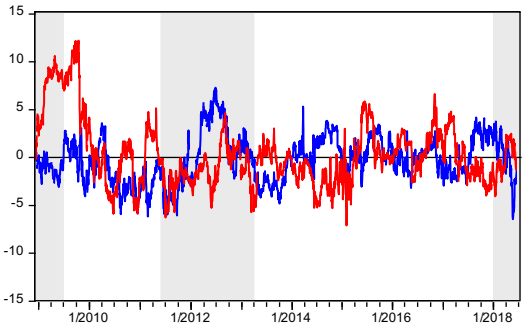

— EUA_EITB - OIL_ELTB

Fig.7. Rolling "NET PAIRWISE” volatility spillovers of EUA and OIL

Note: The net pairwise volatility spillover index is the difference between the volatility transmitted from one market to another and the volatility received by that one market from the other. Hence the positive values imply that the first market transmits more volatility information to the second, whereas the negative values mean that the second markets send more volatility information to the first one. The blue area represents the net pairwise volatility spillovers between EUA and each energy asset, while the blue and red lines depict the net pairwise volatility spillovers of EUA and OIL with non-energy financial assets respectively. Shaded areas denote EU economic recessions as defined by the CEPR.

Fig. 7 depicts distinctive connectedness dynamics in terms of volatility. Particularly, there is a big gap between the connectedness of EUA and OIL with non-energy financial assets. More specifically, with regard to the volatility linkages of EUA-energy, EUA acts as a net transmitter to both GAS and EPE but performs as a net receiver from OIL instead of COAL (recall V1 of Fig. 2). This finding signifies that from a dynamic perspective, the oil market tends to transmit market sentiment, including fear and panic, to the electricity and gas markets through the carbon market, which further supports the results in Ji et al. (2018). Interestingly, different to the static manner, as a net transmitter (see V1 of Fig.2), COAL connects with EUA dynamically with an unclear role since EUA tends to be a net transmitter during the recession but a net receiver from 2014 to 2018, indicating the risk contribution 
of COAL to EUA is increasing. This result is corroborated by Fig. 2 (see V3-V5) which indicates that EUA transmitted more volatility to COAL before the structural break in 2010, but thereafter received more from COAL.

Furthermore, the variability of the interactions between EUA and finance is relatively distinct compared with that of OIL-finance. First, for the interaction with ESTOXX, both EUA and OIL contribute less than they receive during the whole sample and recessions; this implies the stock market is a risk trigger for commodity markets. This finding corresponds to the information in Fig.2 (see V1 and V2), which partly supports the findings of Singh et al. (2019) and Wei and Lin (2016). Second, in terms of NCIR, EUA tends to be a net receiver, and the role of OIL is unclear, which suggests that the oil market is more influential for non-energy commodities (Singh et al., 2019). This result is further supported by Fig. 2 which shows that EUA tends to be a significant net receiver of NCIR, especially during the economic recovery periods (see V3-V5), while the OIL and NCIR are inclined to transmit risk information to each other with a similar intensity which is much stronger than that of EUA-NCIR linkage (see V1-V5). Further, EUA (OIL) tends to be a net receiver (transmitter) of ESTB during the whole sample period; however, their roles reverse during times of economic turmoil. This finding is partly consistent with Fig. 2 which shows that after the break in 2010, OIL tends to receive more net risks from ESTB while EUA is inclined to contribute more net risks to ESTB (see V3-V5). Finally, as supported by Fig. 2 (see V1), the roles of both EUA and OIL are not clear for ECRS and ELTB during the whole sample, which may be caused by the weak volatility linkages among them.

\subsection{Macroeconomic determinants of system-wide connectedness}

\subsubsection{Macroeconomic factors selection}

In this section, we further seek to explore (i) if the total spillovers in the "Carbon-Energy-Finance" system are affected by macroeconomic factors; and (ii) which variable (group) contributes more to total spillovers. We investigate the macroeconomic determinants of four dependent variables sourced from Section 5.2.1: (i) ALL_total return spillover index (TRS); (ii) ALL_total volatility spillover index

(TVS), (iii) EUA_OIL_finance_total return spillover index (EOFRS), and (iv) EUA_OIL_finance_total volatility spillover index (EOFVS). For the independent variables, we define two categories of macroeconomic factors: (i) Commodity-type macroeconomic factors, which tend to 
affect the real commodity supply and demand directly through the macroeconomic cycle, and (ii) Financial risk-type macroeconomic factors, which tend to influence the expectations of investors significantly and thus lead to the change of funds flow.

In terms of the Commodity-type macroeconomic factors, four monthly common variables are used: (i) change ratio of the real effective exchange rate of the Euro Area (denoted by EExR); (ii) change in global demand for commodity (denoted by GDC), defined as the change ratio of the index of global real economic activity in industrial commodity markets proposed in Kilian (2009); (iii) inflation rate of the Euro Area (denoted by Inf); and (iv) change ratio of the industrial production index in the European Union (denoted by IPI). Additionally, the five monthly Financial risk-type macroeconomic factors are (i) lag of the dependent variable (denoted by TRS1, EOFRS1, TVSl, and EOFVS1), (ii) change ratio of the US dollar index (denoted by UDI), (iii) change ratio of the consumer confidence index of the European Union (denoted by CCI), (iv) change ratio of global economic policy uncertainty index constructed in Davis (2016) (denoted by GEPU), and (v) change ratio of the CBOE volatility index (denoted by VIX).

We use the last observation of each month as the monthly data of the daily frequency variable (i.e., four dependent variables and VIX). In addition, the change ratio of each variable (except Inf) is computed as $\left(P_{t}-P_{t-1}\right) / P_{t-1}$, and these ratios are found to be stationary. The source and transformations of the aforementioned data can be found in Appendix A2.

\subsubsection{Contributions of macroeconomic factors}

Table 3 reports the empirical results regarding the influences of the macroeconomic factors on the four total spillover indices using both bivariate and multivariate regression models. For the multivariate regressions, we further estimate the contribution of each variable to the variance of the dependent variable. Following Ma et al. (2019), we adopt Shapley's (1953) concept to estimate the exact contribution of each explanatory variable to the regression R-square. In addition to the single contribution of each macroeconomic factor, we further estimate the contributions of two groups: (i) Group FIN, which contains five financial risk-type macroeconomic variables, and (ii) Group COMM, which contains four commodity-type macroeconomic variables.

Generally, from Table 3, we find that the total return and volatility spillovers are dominated by the Financial risk-type macroeconomic factors, which partly supports the results of Koch (2014) and 
Zheng et al. (2015). For instance, the total return spillovers are significantly determined by the US dollar index and VIX, and the total volatility spillovers are mainly affected by the global economic policy uncertainty index. Specifically, Panels A1 and A2 exhibit the influence of macroeconomic factors on the TRS using the bi- and multivariate regressions, respectively. Obviously, the influences of the US dollar index and VIX are considerable in both the bi- and multivariate regressions. However, there is limited support for the Commodity-type macroeconomic factors being strongly linked to the total return spillovers as the inflation rate is only statistically significant in the bivariate regressions. The negative effect of the US dollar index indicates that a rise in the US dollar index tends to decrease the return linkages in the "Carbon-Energy-Finance" system and vice versa. This finding may be attributed to the significance of the US dollar index for currency markets, commodity markets, and bond markets. For instance, when the US dollar index rises, the funds in European countries tend to flow into US bond markets, significantly reducing the investment activities and expectation connectedness in the "Carbon-Energy-Finance" system. Additionally, the positive influence of VIX may be explained as follows: the increased VIX pulls up the adjustments of investment portfolio strategies in the "Carbon-Energy-Finance" system, increasing the system-wide return connectedness. The significantly negative effect of inflation in the bivariate regression demonstrates that the drop in inflation rate tends to cause the increase in total expectation linkages among the "Carbon-EnergyFinance" system. This result may be owing to the fact that a decrease in the inflation rate represents a fall in demand or even a recession, thereby raising risk aversion of investors and triggering investment portfolio adjustments in the "Carbon-Energy-Finance" system. The Shapley decomposition of Rsquared indicates that the Group FIN (Financial risk-type macroeconomic factors) is the dominant driver of the system-wide return connectedness, with the contribution reaching $66.77 \%$. By comparison, VIX is the most important factor, contributing more than one third, followed by the US dollar index and inflation with contributions of more than $20 \%$.

Noticeably, in Panels B1 and B2, the contribution of financial risk-type macroeconomic factors to the R-squared of EOFRS is dominant; it is almost triple of the Commodity-type macroeconomic factors. Likewise, the negative influence of the US dollar index and the positive effect of VIX on EOFRS remain considerable at the $10 \%$ significance level, with each contribution being approximately $30 \%$. However, no evidence is found of a significant relationship between Commodity-type 
macroeconomic factors and EOFRS. Interestingly, the GEPU contributes approximately 13\% to Rsquared but only affects EOFRS positively at the $10 \%$ significance level in the bivariate regression. This finding suggests that the connectedness with financial assets is more likely to be influenced by the global economic policy uncertainty index because its increase will sharply raise the panic sentiment of investors in the financial markets, thereby increasing the investment portfolio strategy adjustments and connectedness in the system.

According to the results presented in Panels $\mathrm{C}$ and $\mathrm{D}$, we are surprised to find that the macroeconomic factors affect total return spillovers and total volatility spillovers through distinctive paths. First, the influence of financial risk-type macroeconomic factors on the volatility connectedness is more considerable since the contribution to volatility spillovers (approximately 90\%) is much higher than that to return spillovers (approximately 70\%). Second, for the total volatility spillovers, the global economic policy uncertainty index is more important than the US dollar index and VIX. In addition, the TVS tends to be affected by its historical value significantly, with a contribution of over $33 \%$, and the EOFVS is more likely to be determined by CCI, with a contribution of nearly $35 \%$. The positive connection between GEPU and two total volatility spillovers can be explained by the following: the increase in the global economic policy uncertainty index escalates the panic of investors, leading to the increase in fear connectedness in the "Carbon-Energy-Finance" system. By contrast, the negative relationship between TVSI and TVS may be caused by the frequent change in investment sentiment because the sentiment of investors' returns to the balance point once the shock from the related market has been digested. The negative influence of CCI on EOFVS may be owing to the close relationship between economic leading variables and financial markets, that is, the increase in the CCI signifies a positive economic prospect, which tends to reduce the risk spillovers among financial markets.

Table 3 The estimation results and contributions of macroeconomic factors for the dynamic total spillovers.

\begin{tabular}{|c|c|c|c|c|c|c|c|c|}
\hline \multirow{2}{*}{$\begin{array}{c}\text { Dependent } \\
\text { variable: } \boldsymbol{T} \boldsymbol{R} S\end{array}$} & \multicolumn{3}{|c|}{ Panel A1: Bivariate } & \multicolumn{5}{c|}{ Panel A2: Multivariate } \\
\cline { 2 - 9 } & $\boldsymbol{B}$ & $\boldsymbol{t}$ & $\boldsymbol{R}$-sq & $\boldsymbol{\beta}$ & $\boldsymbol{t}$ & $\boldsymbol{R}$-sq & $\begin{array}{c}\text { Shapley } \\
\text { value }\end{array}$ & $\begin{array}{c}\text { Contribution } \\
(\%)\end{array}$ \\
\hline TRSI & 0.042 & 0.44 & 0.002 & 0.095 & 1.00 & & 0.005 & $\mathbf{4 . 0 4}$ \\
\hline UDI & -0.122 & $-1.99^{* *}$ & 0.034 & -0.126 & $-1.88^{*}$ & & 0.033 & $\mathbf{2 6 . 7 4}$ \\
\hline CCI & -0.007 & -0.39 & 0.001 & -0.002 & -0.12 & & 0.001 & $\mathbf{0 . 5 7}$ \\
\hline GEPU & 0.007 & 0.84 & 0.006 & 0.004 & 0.40 & & 0.003 & $\mathbf{2 . 7 6}$ \\
\hline VIX & 0.017 & $2.16^{* *}$ & 0.040 & 0.018 & $2.27 * *$ & & 0.042 & $\mathbf{3 3 . 6 6}$ \\
\hline EExR & 0.100 & 0.59 & 0.003 & 0.088 & 0.48 & & 0.004 & $\mathbf{2 . 8 5}$ \\
\hline GDC & 0.001 & 0.80 & 0.006 & 0.001 & 0.89 & & 0.007 & $\mathbf{5 . 3 3}$ \\
\hline
\end{tabular}




\begin{tabular}{|c|c|c|c|c|c|c|c|c|}
\hline Inf & -0.007 & $-2.07 * *$ & 0.037 & -0.006 & -1.50 & & 0.029 & 23.60 \\
\hline IPI & 0.000 & 0.10 & 0.000 & -0.000 & -0.08 & 0.125 & 0.001 & 0.45 \\
\hline Group FIN & & & & & & & 0.083 & 66.77 \\
\hline Group COMM & & & & & & & 0.042 & 33.23 \\
\hline \multirow{2}{*}{$\begin{array}{l}\text { Dependent } \\
\text { variable: } \\
\text { EOFRS }\end{array}$} & \multicolumn{3}{|c|}{ Panel B1: Bivariate } & \multicolumn{5}{|c|}{ Panel B2: Multivariate } \\
\hline & $B$ & $t$ & $R-s q$ & $\boldsymbol{\beta}$ & $t$ & $R-s q$ & $\begin{array}{c}\text { Shapley } \\
\text { value }\end{array}$ & $\begin{array}{c}\text { Contribution } \\
\text { (\%) }\end{array}$ \\
\hline EOFRSl & 0.048 & 0.51 & 0.002 & 0.070 & 0.75 & & 0.003 & 2.14 \\
\hline UDI & -0.313 & $-2.55^{* *}$ & 0.055 & -0.303 & $-2.31 * *$ & & 0.051 & 31.81 \\
\hline CCI & -0.031 & -0.84 & 0.006 & -0.006 & -0.17 & & 0.003 & 1.70 \\
\hline GEPU & 0.032 & $1.80^{*}$ & 0.028 & 0.024 & 1.32 & & 0.020 & 12.55 \\
\hline VIX & 0.035 & $2.26 * *$ & 0.044 & 0.038 & $2.44 * *$ & & 0.046 & 28.77 \\
\hline EExR & 0.515 & 1.53 & 0.020 & 0.378 & 1.05 & & 0.016 & 9.71 \\
\hline GDC & 0.001 & 0.44 & 0.002 & 0.001 & 0.77 & & 0.004 & 2.19 \\
\hline Inf & -0.010 & -1.47 & 0.019 & -0.007 & -0.91 & & 0.014 & 8.90 \\
\hline IPI & -0.002 & -0.56 & 0.003 & -0.003 & -0.63 & 0.160 & 0.004 & 2.22 \\
\hline Group FIN & & & & & & & 0.121 & 75.37 \\
\hline Group COMM & & & & & & & 0.039 & 24.63 \\
\hline \multirow{2}{*}{$\begin{array}{c}\text { Dependent } \\
\text { variable: } T V S\end{array}$} & \multicolumn{3}{|c|}{ Panel C1: Bivariate } & \multicolumn{5}{|c|}{ Panel C2: Multivariate } \\
\hline & $B$ & $t$ & $R-s q$ & $\boldsymbol{\beta}$ & $t$ & $R-s q$ & $\begin{array}{c}\text { Shapley } \\
\text { value }\end{array}$ & $\begin{array}{c}\text { Contribution } \\
\text { (\%) }\end{array}$ \\
\hline TVS1 & -0.204 & $-2.24 * *$ & 0.043 & -0.224 & $-2.36^{* *}$ & & 0.046 & 33.80 \\
\hline UDI & -0.036 & -0.48 & 0.002 & -0.031 & -0.39 & & 0.002 & 1.33 \\
\hline CCI & -0.024 & -1.10 & 0.011 & -0.014 & -0.62 & & 0.007 & 5.02 \\
\hline GEPU & 0.028 & $2.67 * * *$ & 0.060 & 0.023 & $2.05 * *$ & & 0.047 & 34.74 \\
\hline VIX & 0.014 & 1.50 & 0.020 & 0.011 & 1.15 & & 0.015 & 11.30 \\
\hline EExR & 0.297 & 1.45 & 0.019 & 0.252 & 1.13 & & 0.015 & 11.11 \\
\hline GDC & -0.001 & -0.51 & 0.002 & -0.000 & -0.23 & & 0.001 & 0.91 \\
\hline Inf & 0.001 & 0.30 & 0.001 & 0.002 & 0.47 & & 0.002 & 1.28 \\
\hline IPI & -0.000 & -0.12 & 0.000 & 0.001 & 0.33 & 0.136 & 0.001 & 0.50 \\
\hline Group FIN & & & & & & & 0.117 & 86.07 \\
\hline Group COMM & & & & & & & 0.019 & 13.93 \\
\hline \multirow{2}{*}{$\begin{array}{l}\text { Dependent } \\
\text { variable: } \\
\text { EOFVS }\end{array}$} & \multicolumn{3}{|c|}{ Panel D1: Bivariate } & \multicolumn{5}{|c|}{ Panel D2: Multivariate } \\
\hline & $B$ & $t$ & $R-s q$ & $\boldsymbol{\beta}$ & $t$ & $R-s q$ & $\begin{array}{c}\text { Shapley } \\
\text { value }\end{array}$ & $\begin{array}{l}\text { Contribution } \\
\text { (\%) }\end{array}$ \\
\hline EOFVSl & -0.068 & -0.72 & 0.005 & -0.109 & -1.14 & & 0.008 & 6.11 \\
\hline UDI & 0.149 & 0.99 & 0.009 & 0.191 & 1.20 & & 0.010 & 7.48 \\
\hline CCI & -0.116 & $-2.68 * * *$ & 0.060 & -0.094 & $-2.05^{* *}$ & & 0.048 & 34.96 \\
\hline GEPU & 0.051 & $2.43 * *$ & 0.050 & 0.037 & $1.69^{*}$ & & 0.036 & 26.36 \\
\hline VIX & 0.030 & 1.59 & 0.022 & 0.022 & 1.17 & & 0.017 & 12.09 \\
\hline EExR & 0.493 & 1.21 & 0.013 & 0.404 & 0.90 & & 0.010 & 6.97 \\
\hline GDC & -0.000 & -0.12 & 0.000 & 0.001 & 0.47 & & 0.001 & 0.49 \\
\hline $\operatorname{Inf}$ & -0.003 & -0.41 & 0.002 & -0.006 & -0.70 & & 0.003 & 2.19 \\
\hline IPI & -0.003 & -0.52 & 0.002 & -0.005 & -0.90 & 0.137 & 0.005 & 3.34 \\
\hline Group FIN & & & & & & & 0.123 & 89.78 \\
\hline Group COMM & & & & & & & 0.014 & 10.22 \\
\hline
\end{tabular}

Note: The monthly sample ranges from February 2009 to July 2018. Panel A1 and A2 report the bivariate and multivariate regression results respectively in terms of the influence of macroeconomic factors on TRS (i.e. Total return spillovers). Panel B1 and B2 report the bivariate and multivariate regression results respectively regarding the influence of macroeconomic factors on EOFRS (i.e. EUA-OIfinance total return spillovers). Likewise, Panel $\mathrm{C} 1$ and $\mathrm{C} 2$ exhibit the bivariate and multivariate regression results respectively for the influence of macroeconomic factors on TVS (i.e. Total volatility spillovers). Panel D1 and D2 display the bivariate and multivariate regression results respectively for the effect of macroeconomic factors on EOFVS (i.e. EUA-OIL-finance total volatility spillovers). The column $\beta$ (B) reports the slope coefficient, $t$ is the t-statistic value for the slope coefficient. R-sq is the coefficient of determination. *, 
**, *** are significant at $10 \%, 5 \%$, and $1 \%$ level respectively. TRSl, EOFRS1, TVSl, and EOFVSl are the lag of four dependent variables (i.e. TRS, EOFRS, TVS, EOFVS) respectively. UDI refers to the US dollar index; CCI is the Consumer Confidence Index of European Union; GEPU is the global economic policy uncertainty index; VIX is the CBOE Volatility Index; EExR is the real effective exchange rate of Euro Area; GDC refers to Global Demand for Commodity; Inf is the inflation rate of Euro Area; IPI is the Industrial Production Index of European Union. Group FIN contains five financial risk factors, including the lag of dependent variable, UDI, CCI, GEPU, and VIX. Group COMM includes other four commodity factors: EExR, GDC, Inf, and IPI. Shapley value (Shapley, 1953) is calculated to determine the exact contribution of each explanatory variable to the regression R-square, and the specific percentage term of contribution is shown in the column Contribution.

\section{Conclusions}

The immense attention on climate change has stimulated increasing interest in incorporating carbon market assets into investment portfolio. For this reason, this paper seeks to shed light on the system-wide return and volatility connectedness between EUA and selected commodity, equity and bond market assets. In particular, this paper investigates: (i) whether the EUA is closely connected with both energy and non-energy financial assets? (ii) what the difference between EUA and OIL is in terms the connectivity with non-energy financial assets? and (iii) which macroeconomic factor is responsible for the total connectivity in the "Carbon-Energy-Finance" system? To our knowledge, this is the first paper to examine these questions within the context of a "Carbon-Energy-Finance" system by employing the modified Lanne-Nyberg (2016) DY spillover index technique.

This approach reveals the spillover hierarchy, magnitude, directions and patterns in the "CarbonEnergy-Finance" system. In addition, the combination of network graphs and structural breaks detected by ICSS algorithm helps to examine connectedness patterns of the EUA with the system in four subsamples. Further, a detailed comparative analysis of EUA and OIL in terms of the interaction with non-energy financial assets is performed to identify any differences or similarities between them. Finally, based on the system-wide spillover indices, the possible macroeconomic determinants of connectedness are investigated via regression models and the Shapley value.

Through comparison with the existing literature, our findings are summarized as follows. First, the return linkage in the "Carbon-Energy-Finance" system is higher than the volatility linkage for the full sample, and this finding is relatively robust to the sample length, date frequency and stock index variable used. Second, the total spillover indices evolve over time and are mainly driven by financial risk-type macroeconomic factors instead of commodity-type macroeconomic factors. For example, the return spillovers are determined by the US dollar index and VIX, while the volatility spillovers are driven by the lags, consumer confidence index, and global economic policy uncertainty index. Third, the EUA tends to connect more closely with energy assets than financial assets as its strongest linkages 
with non-energy commodity and stock markets are weaker than that of OIL and average level. Fourth, the network diagrams in four subsamples divided by three structural breaks indicate that the connectedness of EUA with the system are sensitive to a 2010 shock identified as a structural break as both the return and volatility linkages of EUA-energy and EUA-finance exhibit a sharp plunge during that period of uncertainty (after the break in 2010). Fifth, OIL acts as net transmitter of the system, and EUA acts as a net volatility receiver but plays an unclear role in return connectedness, which implies that carbon volatility instead of return is more likely to be affected by shocks from other markets. Sixth, across the entire sample, EUA acts as a net receiver of information from the oil market and a transmitter to the electricity market, both in terms of return and volatility connectedness; however, EUA tends to act as a net return receiver from the coal market and a net volatility transmitter to the gas market. Seventh, EUA displays a very similar pattern to OIL, in the return connectedness with each financial asset despite the interactions between OIL and financial assets being much closer. For example, the stock market and long-term government bond market are main return triggers for EUA and OIL, where the T-bill rate tends to receive more return spillovers from EUA and OIL. However, the roles of EUA and OIL for both the non-energy commodity and junk bond markets are unclear during the whole sample period. Eighth, EUA and OIL exhibit distinct volatility connectedness with each financial asset, for example, during the whole sample; EUA tends to be a net receiver of the stock market, non-energy commodity markets, and T-bill market, where only OIL tends to be a net receiver of the stock market.

These results are of potential interest to economic agents, including international investors, portfolio managers, and policymakers. These agents require a better understanding of the dynamic spillovers in the "Carbon-Energy-Finance" system in order to build efficient and robust risk hedging models or when formulating policy. Generally, the evidence of unstable linkages in the "CarbonEnergy-Finance" system suggests that there is a need for continuous monitoring of the evolving connectedness network if indeed this information is going to be used to inform investment and policy decision making. Several suggestions based on the empirical results are provided as follows.

Firstly, our findings provide a foundation for policymakers to design a "road map" of the risk network across these assets during different periods and track risk triggers (e.g., Consumer confidence index; Global economic policy uncertainty index) of the system-wide spillovers, which could help 
protect against contagion risk and maintain the stability of the carbon market. Specifically, coal and stock markets should be carefully monitored since they are main risk sources of the carbon market with the strongest risk linkages. In addition, the non-energy commodity, crude oil and long-term bond markets tend to become the main risk sources of the carbon market during times of economic recovery, while the risk spillovers from the corporate bond market to the carbon market should be inspected during times of growth.

Secondly, we find evidence of predictability of carbon price volatility arising from the volatility transmission mechanism between the carbon market and related markets. In particularly, our empirical results show that coal, stock, crude oil, non-energy commodities and T-bills rates all have predictive power for EUA volatility, shown by the net volatility receiver role of EUA in many cases. Meanwhile, EUA is seen to play an important role in the electricity volatility predictability, as demonstrated by the strong volatility spillover from the carbon market to the electricity market.

Finally, our return spillover results are informative for investors and portfolio managers, in that: (i) since the carbon market is not strongly connected to the non-energy financial markets, particularly the bond markets, there may be diversification opportunities to exploit; (ii) attention should be paid to financial risk-type macroeconomic indicators, such as the US dollar index and VIX, as these indicators tend to increase the return linkages between carbon and related markets, thereby weakening the attractiveness of portfolio diversification across the carbon and non-energy financial markets; (iii) portfolio rebalancing between the stock index (non-energy commodity index) and EUA may be necessary given their significant return connectedness during times of economic uncertainty and recession (during periods of recovery and growth) respectively; (iv) the investment portfolios with carbon assets can be beneficial to the risk averse investors seeking risk reduction since the carbon asset may not enhance returns due to its weak historical performance and potential transaction costs, but including carbon assets should help reduce the volatility of an optimized portfolio; (v) coal futures, stock index and non-energy commodity index have a potential role in hedging against carbon exposure during EU economic recessions due to their relatively stable and strong return spillovers to EUA; this is especially worthwhile for future research to investigate. Note that the undertaking of the above hedging strategies may be restricted by the lack of liquidity in the carbon market compared to conventional markets. Liquid future contracts with the same expiration date would need to exist for 
both the carbon and energy assets (or stock and non-energy commodity assets). The carbon market remains relatively new and is continuing to develop and grow; new products are now being used including carbon ETFs and more investors are active which is continuously raising liquidity. Thus, we anticipate the carbon market will be broadly accessible to a wide range of investors in the near future.

\section{Acknowledgments:}

We sincerely thank the editor and the anonymous reviewers of this paper. The first author would like to acknowledge the support of the UK-China Joint Research and Innovation Partnership Fund PhD Placement Programme (No. 201703780042). This work was financially supported by the Natural Science Foundation of China [grant number 71871215, 71701201]. 


\section{Appendix A1. Data description for Sections 5.1 and 5.2}

This appendix details the variables used in Sections 5.1 and 5.2, including any transformations conducted. The Euro-area bond yields are from the ECB and the ICE Natural Gas price is from QUANDL, all other variables are from Datastream including the Corporate Bond Return Spread.

(1) Euro-area 3-month bond yield (ESTB), continuously compounded yield in \% per annum. Transformation: take the first-order difference of the continuously compounded yield sequence.

(2) Euro-area 10-year bond yield (ELTB), continuously compounded yield in \% per annum. Transformation: take the first-order difference of the continuously compounded yield sequence (3) ICE-EUA futures (EUA), price in EUR/ton of $\mathrm{CO}_{2}$.

Transformation: take the difference between the logarithms of two contiguous prices.

(4) ICE-Brent Crude futures (OIL), price in USD/barrel.

Transformation: take the difference between the logarithms of two contiguous prices.

(5) ICE-API2 Rotterdam Coal futures (COAL), price in USD/ton.

Transformation: take the difference between the logarithms of two contiguous prices.

(6) ICE-UK Natural Gas futures (GAS), price in Sterling and pence/Therm.

Transformation: take the difference between the logarithms of two contiguous prices.

(7) EEX-Phelix Electricity Baseload futures (EPE), price in EUR/MWh.

Transformation: take the difference between the logarithms of two contiguous prices.

(8) S\&P GSCI Non-Energy Commodity Total Return index (NCIR).

Transformation: take the difference between the logarithms of two contiguous prices.

(9) Euro corporate bond return spread (ECRS).

Transformation: calculate the logarithms returns of two contiguous prices for FISE euro corporate bond rated $\mathrm{BBB}$ and $\mathrm{AAA}$ respectively, and then find the difference between these two returns.

(10) STOXX EUROPE 600 Index (ESTOXX)

Transformation: take the difference between the logarithms of two contiguous prices. 


\section{Appendix A2. Data description for Section 5.3}

This appendix details the variables used in Section 5.3, including transformations conducted.

(1) Four total spillover indices (TRS, EOFRS, TVS, and EOFVS), daily, generated from the estimation results in Section 5.2

Transformation: take the last observation of each month as the representative value of the corresponding month, and then compute the monthly change ratio based on $\left(P_{t}-P_{t-1}\right) / P_{t-1}$.

(2) The lag of dependent variables: TRS1, EOFRS1, TVSl, and EOFVSl, monthly

Transformation: take the first lag of TRS, EOFRS, TVS, and EOFVS, respectively.

(3) US dollar index (UDI), monthly, sourced from Datastream

Transformation: compute the change ratio of US dollar index via $\left(P_{t}-P_{t-1}\right) / P_{t-1}$.

(4) CBOE Volatility Index (VIX), daily, sourced from Datastream

Transformation: take the last observation of each month as the representative value of the corresponding month, and then compute the monthly change ratio based on $\left(P_{t}-P_{t-1}\right) / P_{t-1}$.

(5) Consumer confidence index of European Union (CCI), monthly, sourced from Datastream Transformation: compute the monthly change ratio based on $\left(P_{t}-P_{t-1}\right) / P_{t-1}$.

(6)Global Economic Policy Uncertainty Index, monthly, sourced from website: http://policyuncertainty.com

Transformation: compute the monthly change ratio based on $\left(P_{t}-P_{t-1}\right) / P_{t-1}$.

(7) The real effective exchange rate of Euro Area (EExR), monthly, generated from Eurostat database

Transformation: compute the monthly change ratio based on $\left(P_{t}-P_{t-1}\right) / P_{t-1}$.

(8) Inflation rate (Inf), monthly, generated from Eurostat database.

(9) Industrial Production Index of European Union (IPI), monthly, sourced from Eurostat database Transformation: compute the monthly change ratio based on $\left(P_{t}-P_{t-1}\right) / P_{t-1}$.

(10) Index of global real economic activity in industrial commodity markets (GDC), monthly, obtained from http://sites.google.com/site/lkilian2019/research/data-sets

Transformation: compute the monthly change ratio based on $\left(P_{t}-P_{t-1}\right) / P_{t-1}$. 
Appendix B1. Static return and volatility connectedness matrix of "Carbon-Energy-Finance" system with sample including Phase I.

\begin{tabular}{|c|c|c|c|c|c|c|c|c|c|c|c|}
\hline Obs. $=3067$ & EUA & $\mathrm{EPE}$ & GAS & OIL & COAL & NCIR & ESTOXX & ECRS & ESTB & ELTB & $\begin{array}{l}\text { Directional } \\
\text { from Others }\end{array}$ \\
\hline \multicolumn{12}{|c|}{ Panel A: return connectedness (\%) } \\
\hline EUA & 53.65 & 5.73 & 3.76 & 5.54 & 0.90 & 13.54 & 4.17 & 2.99 & 1.12 & 8.61 & 46.35 \\
\hline EPE & 2.63 & 68.16 & 2.32 & 0.68 & 4.54 & 7.61 & 2.88 & 1.66 & 2.51 & 7.00 & 31.84 \\
\hline GAS & 0.14 & 0.18 & 65.72 & 7.00 & 18.08 & 2.09 & 4.69 & 0.89 & 0.43 & 0.79 & 34.28 \\
\hline OIL & 0.13 & 0.11 & 2.70 & 53.48 & 8.68 & 16.29 & 12.64 & 0.79 & 1.84 & 3.34 & 46.52 \\
\hline COAL & 0.22 & 0.28 & 9.66 & 11.32 & 60.08 & 3.66 & 9.18 & 1.43 & 2.82 & 1.36 & 39.92 \\
\hline NCIR & 0.20 & 0.18 & 0.81 & 16.42 & 2.15 & 55.61 & 16.49 & 1.69 & 2.11 & 4.35 & 44.39 \\
\hline ESTOXX & 0.11 & 0.21 & 1.77 & 12.22 & 5.93 & 15.86 & 47.21 & 2.83 & 1.77 & 12.10 & 52.79 \\
\hline ECRS & 0.09 & 0.36 & 1.54 & 4.88 & 1.19 & 6.24 & 13.75 & 65.17 & 1.15 & 5.62 & 34.83 \\
\hline ESTB & 0.22 & 0.39 & 2.24 & 3.49 & 4.14 & 6.37 & 11.19 & 2.50 & 60.87 & 8.59 & 39.13 \\
\hline ELTB & 0.05 & 0.49 & 0.82 & 4.43 & 0.91 & 5.61 & 15.18 & 0.86 & 2.21 & 69.44 & 30.56 \\
\hline Directional to others & 3.79 & 7.93 & 25.63 & 65.97 & 46.51 & 77.27 & 90.17 & 15.62 & 15.96 & 51.76 & \\
\hline Net spillovers & -42.57 & -23.91 & -8.66 & 19.45 & 6.59 & 32.89 & 37.38 & -19.20 & -23.17 & 21.20 & 40.06 \\
\hline \multicolumn{12}{|c|}{ Panel B: volatility connectedness (\%) } \\
\hline EUA & 56.11 & 8.10 & 6.06 & 4.10 & 1.83 & 6.54 & 3.90 & 3.31 & 1.09 & 8.96 & 43.89 \\
\hline EPE & 1.55 & 65.15 & 8.82 & 2.39 & 4.26 & 3.43 & 4.64 & 3.69 & 0.76 & 5.31 & 34.85 \\
\hline GAS & 0.15 & 1.60 & 73.25 & 2.66 & 8.41 & 2.88 & 1.10 & 6.88 & 0.29 & 2.77 & 26.75 \\
\hline OIL & 0.12 & 0.50 & 0.56 & 66.84 & 7.98 & 8.62 & 10.41 & 1.47 & 1.48 & 2.03 & 33.16 \\
\hline COAL & 0.22 & 0.32 & 3.44 & 10.25 & 68.64 & 5.05 & 6.73 & 1.64 & 3.10 & 0.60 & 31.36 \\
\hline NCIR & 0.07 & 0.47 & 1.41 & 7.58 & 4.19 & 66.63 & 12.41 & 0.65 & 2.87 & 3.71 & 33.37 \\
\hline ESTOXX & 0.06 & 0.37 & 0.86 & 7.71 & 3.94 & 12.34 & 59.12 & 1.09 & 4.16 & 10.35 & 40.88 \\
\hline ECRS & 0.12 & 0.43 & 2.81 & 0.76 & 0.79 & 2.02 & 6.25 & 69.38 & 0.76 & 16.68 & 30.62 \\
\hline ESTB & 0.05 & 0.38 & 3.18 & 6.05 & 6.34 & 12.19 & 14.45 & 1.33 & 51.31 & 4.71 & 48.69 \\
\hline ELTB & 0.14 & 0.40 & 0.36 & 1.38 & 1.04 & 3.34 & 11.21 & 9.06 & 1.82 & 71.24 & 28.76 \\
\hline Directional to others & 2.49 & 12.58 & 27.51 & 42.88 & 38.79 & 56.41 & 71.12 & 29.13 & 16.32 & 55.12 & \multirow{2}{*}{35.23} \\
\hline Net spillovers & -41.40 & -22.27 & 0.76 & 9.72 & 7.43 & 23.03 & 30.23 & -1.49 & -32.37 & 26.36 & \\
\hline
\end{tabular}

Notes: The results in this table are based on the 3067 daily observations ranging from 7/18/2006 to 7/17/2018 (including the Phase I of EU ETS). The inner matrix represents pairwise spillover. The light blue shaded region represents system-wide "FROM" and "TO" spillover. The deep blue shaded region represents system-wide "NET" spillover. The green shaded region exhibits the pairwise spillover between EUA and financial assets, while the orange shaded region displays the pairwise spillover between OIL and financial assets. The extreme right bottom corner value of the matrix represents system-wide "TOTAL" spillover. 
Appendix B2. Static return and volatility connectedness matrix of "Carbon-Energy-Finance" system with carbon-intensive ESTOXX variable.

\begin{tabular}{|c|c|c|c|c|c|c|c|c|c|c|c|}
\hline Obs. $=2651$ & EUA & $\mathrm{EPE}$ & GAS & OIL & COAL & NCIR & ESTOXX & ECRS & ESTB & ELTB & $\begin{array}{l}\text { Directional } \\
\text { from Others }\end{array}$ \\
\hline \multicolumn{12}{|c|}{ Panel A: return connectedness (\%) } \\
\hline EUA & 59.02 & 0.31 & 6.11 & 6.75 & 8.34 & 5.41 & 8.13 & 0.45 & 0.70 & 4.78 & 59.02 \\
\hline EPE & 3.15 & 66.01 & 5.02 & 1.33 & 4.51 & 6.77 & 3.27 & 1.54 & 2.07 & 6.34 & 3.15 \\
\hline GAS & 7.73 & 0.25 & 59.55 & 6.52 & 17.55 & 1.48 & 4.64 & 0.73 & 0.31 & 1.24 & 7.73 \\
\hline OIL & 4.32 & 0.07 & 3.43 & 49.41 & 7.98 & 15.18 & 13.79 & 0.64 & 1.87 & 3.30 & 4.32 \\
\hline COAL & 6.33 & 0.27 & 12.12 & 9.60 & 54.88 & 2.89 & 9.01 & 1.07 & 2.74 & 1.11 & 6.33 \\
\hline NCIR & 4.34 & 0.29 & 0.90 & 15.48 & 1.88 & 51.18 & 18.13 & 1.60 & 2.21 & 3.98 & 4.34 \\
\hline ESTOXX & 5.04 & 0.30 & 2.39 & 12.49 & 5.71 & 15.97 & 43.42 & 2.41 & 1.59 & 10.68 & 5.04 \\
\hline ECRS & 2.44 & 0.38 & 2.26 & 4.56 & 1.30 & 6.04 & 12.98 & 64.07 & 1.17 & 4.80 & 2.44 \\
\hline ESTB & 3.32 & 0.31 & 3.62 & 3.30 & 4.32 & 6.08 & 9.25 & 2.41 & 58.41 & 8.99 & 3.32 \\
\hline ELTB & 2.89 & 0.33 & 1.20 & 4.39 & 0.92 & 5.22 & 14.49 & 0.85 & 2.33 & 67.38 & 2.89 \\
\hline Directional to others & 39.55 & 2.53 & 37.06 & 64.42 & 52.51 & 65.04 & 93.69 & 11.70 & 14.99 & 45.21 & A2 67 \\
\hline Net spillovers & -1.44 & -31.47 & -3.39 & 13.83 & 7.38 & 16.22 & 37.11 & -24.24 & -26.60 & 12.59 & 42.07 \\
\hline \multicolumn{12}{|c|}{ Panel B: volatility connectedness (\%) } \\
\hline EUA & 77.80 & 0.63 & 1.72 & 1.04 & 6.20 & 2.90 & 5.78 & 2.91 & 0.19 & 0.81 & 22.20 \\
\hline EPE & 2.70 & 65.56 & 5.37 & 2.76 & 3.02 & 3.54 & 6.06 & 3.10 & 0.87 & 7.01 & 34.44 \\
\hline GAS & 2.32 & 0.98 & 70.45 & 3.71 & 9.31 & 3.58 & 2.58 & 4.90 & 0.32 & 1.86 & 29.55 \\
\hline OIL & 0.51 & 0.45 & 0.95 & 64.21 & 8.44 & 8.66 & 11.52 & 1.71 & 1.31 & 2.23 & 35.79 \\
\hline COAL & 2.10 & 0.19 & 5.02 & 9.93 & 65.36 & 5.01 & 6.88 & 1.84 & 2.88 & 0.79 & 34.64 \\
\hline NCIR & 1.41 & 0.63 & 1.47 & 7.34 & 4.37 & 63.21 & 14.15 & 0.71 & 2.68 & 4.04 & 36.79 \\
\hline ESTOXX & 2.76 & 0.33 & 1.45 & 8.21 & 4.61 & 12.91 & 55.29 & 1.15 & 3.44 & 9.85 & 44.71 \\
\hline ECRS & 1.98 & 0.47 & 2.67 & 1.02 & 1.14 & 2.47 & 6.37 & 67.68 & 0.63 & 15.56 & 32.32 \\
\hline ESTB & 0.25 & 0.45 & 5.75 & 5.60 & 6.58 & 12.47 & 12.92 & 1.20 & 49.70 & 5.08 & 50.30 \\
\hline ELTB & 0.49 & 0.35 & 0.64 & 1.40 & 1.07 & 3.60 & 11.42 & 9.26 & 1.75 & 70.00 & 30.00 \\
\hline Directional to others & 14.52 & 4.47 & 25.05 & 41.03 & 44.75 & 55.13 & 77.69 & 26.78 & 14.07 & 47.24 & \multirow{2}{*}{35.07} \\
\hline Net spillovers & -7.68 & -29.96 & -4.50 & 5.24 & 10.11 & 18.34 & 32.98 & -5.54 & -36.23 & 17.24 & \\
\hline
\end{tabular}

Notes: The results in this table are based on the 2651 daily observations ranging from 3/4/2008 to 7/17/2018 (excluding the Phase I of EU ETS). In order to check the robustness of ESTOXX, we replaced EUROSTOXX600 index based on all sectors with the EUROSTOXX600 index based on eight Carbon intensive sectors (i.e. Auto \& Parts; Basic Resources; Industrial Goods \& Services; Oil \& Gas; Utilities; Chemicals; Construction \& Materials; Travel \& Leisure). The ESTOXX variable reported in this table is estimated by averaging the EUROSTOXX600 returns/volatility of eight carbon intensive sectors. The inner matrix represents pairwise spillover. The light blue shaded region represents system-wide "FROM" and "TO" spillover. The deep blue shaded region represents system-wide "NET" spillover. The green shaded region exhibits the pairwise spillover between EUA and financial assets, while the orange shaded region displays the pairwise spillover between OIL and financial assets. The extreme right bottom corner value of the matrix represents system-wide "TOTAL" spillover. 
Appendix B3. Static return and volatility connectedness matrix of "Carbon-Energy-Finance" system with weekly data.

\begin{tabular}{|c|c|c|c|c|c|c|c|c|c|c|c|}
\hline Obs. $=540$ & EUA & $\mathrm{EPE}$ & GAS & OIL & COAL & NCIR & ESTOXX & ECRS & ESTB & ELTB & $\begin{array}{l}\text { Directional } \\
\text { from Others }\end{array}$ \\
\hline \multicolumn{12}{|c|}{ Panel A: return connectedness (\%) } \\
\hline EUA & 58.23 & 3.47 & 5.68 & 6.43 & 1.98 & 2.81 & 8.91 & 4.25 & 3.48 & 4.77 & 41.77 \\
\hline EPE & 8.65 & 58.94 & 9.30 & 3.82 & 1.73 & 5.17 & 2.66 & 1.56 & 3.12 & 5.04 & 41.06 \\
\hline GAS & 5.26 & 2.92 & 57.25 & 6.34 & 15.49 & 2.95 & 1.43 & 2.82 & 3.19 & 2.35 & 42.75 \\
\hline OIL & 4.51 & 1.27 & 2.37 & 46.52 & 8.79 & 15.94 & 13.55 & 2.93 & 1.06 & 3.08 & 53.48 \\
\hline COAL & 3.03 & 0.91 & 11.77 & 11.79 & 52.76 & 4.77 & 7.08 & 2.24 & 3.49 & 2.15 & 47.24 \\
\hline NCIR & 2.39 & 2.09 & 2.36 & 15.68 & 3.01 & 47.63 & 13.33 & 4.81 & 3.24 & 5.47 & 52.37 \\
\hline ESTOXX & 1.31 & 2.18 & 1.56 & 13.06 & 6.05 & 11.66 & 42.45 & 10.22 & 3.26 & 8.24 & 57.55 \\
\hline ECRS & 2.15 & 0.36 & 2.13 & 5.28 & 4.04 & 7.55 & 17.47 & 49.89 & 5.97 & 5.15 & 50.11 \\
\hline ESTB & 3.09 & 2.00 & 6.48 & 4.50 & 7.69 & 9.01 & 7.47 & 6.66 & 41.48 & 11.62 & 58.52 \\
\hline ELTB & 1.98 & 1.55 & 2.57 & 4.41 & 2.26 & 6.85 & 10.95 & 2.08 & 8.68 & 58.67 & 41.33 \\
\hline Directional to others & 32.37 & 16.76 & 44.21 & 71.31 & 51.04 & 66.71 & 82.84 & 37.58 & 35.48 & 47.87 & 4860 \\
\hline Net spillovers & -9.41 & -24.30 & 1.46 & 17.83 & 3.80 & 14.34 & 25.30 & -12.52 & -23.04 & 6.54 & 48.62 \\
\hline \multicolumn{12}{|c|}{ Panel B: volatility connectedness (\%) } \\
\hline EUA & 70.40 & 2.04 & 3.04 & 1.94 & 6.35 & 2.97 & 2.19 & 2.58 & 3.33 & 5.16 & 29.60 \\
\hline EPE & 4.29 & 60.50 & 3.82 & 3.42 & 6.62 & 4.11 & 3.16 & 8.46 & 3.65 & 1.98 & 39.50 \\
\hline GAS & 2.38 & 1.55 & 61.29 & 6.08 & 5.92 & 5.48 & 3.15 & 8.22 & 4.38 & 1.55 & 38.71 \\
\hline OIL & 1.29 & 1.70 & 4.83 & 57.33 & 4.92 & 9.30 & 12.12 & 2.72 & 2.70 & 3.08 & 42.67 \\
\hline COAL & 2.17 & 1.37 & 8.07 & 4.54 & 57.35 & 4.17 & 5.22 & 5.44 & 8.36 & 3.31 & 42.65 \\
\hline NCIR & 1.82 & 2.42 & 4.84 & 5.74 & 2.25 & 53.25 & 11.93 & 3.03 & 9.87 & 4.84 & 46.75 \\
\hline ESTOXX & 2.40 & 0.88 & 3.66 & 10.95 & 2.45 & 10.10 & 49.41 & 8.19 & 7.24 & 4.73 & 50.59 \\
\hline ECRS & 1.99 & 0.75 & 2.30 & 2.16 & 1.65 & 4.86 & 10.64 & 52.52 & 2.99 & 20.12 & 47.48 \\
\hline ESTB & 1.19 & 0.67 & 9.84 & 3.09 & 11.05 & 12.47 & 10.19 & 3.14 & 41.29 & 7.08 & 58.71 \\
\hline ELTB & 3.11 & 1.41 & 1.46 & 1.49 & 2.02 & 6.92 & 7.53 & 14.85 & 6.37 & 54.84 & 45.16 \\
\hline Directional to others & 20.64 & 12.79 & 41.86 & 39.41 & 43.24 & 60.37 & 66.13 & 56.62 & 48.89 & 51.85 & \multirow{2}{*}{44.18} \\
\hline Net spillovers & -8.96 & -26.70 & 3.15 & -3.26 & 0.59 & 13.63 & 15.54 & 9.14 & -9.82 & 6.69 & \\
\hline
\end{tabular}

Notes: The results in this table are based on 540 weekly observations ranging from 3/5/2008 to 7/17/2018 (the observation on Wednesday are used). The inner matrix represents pairwise spillover. The light blue shaded region represents system-wide "FROM" and "TO" spillover. The deep blue shaded region represents system-wide "NET" spillover. The green shaded region exhibits the pairwise spillover between EUA and financial assets, while the orange shaded region displays the pairwise spillover between OIL and financial assets. The extreme right bottom corner value of the matrix represents system-wide "TOTAL" spillover. 


\section{Reference}

Aatola, P., Ollikainen, M., Toppinen, A., 2013. Impact of the carbon price on the integrating European electricity market. Energy Policy, 61, 1236-1251. https://doi.org/10.1016/j.enpol.2013.06.036

Acharya, V. V., Pedersen, L. H., 2005. Asset pricing with liquidity risk. J. Financ. Econ. 77(2), 375-410. https://doi.org/10.1016/j.jfineco.2004.06.007

Alberola, E., Chevallier, J., Chèze, B., 2008. Price drivers and structural breaks in European carbon prices 20052007. Energy policy, 36(2), 787-797. https://doi.org/10.1016/j.enpol.2007.10.029

Antonakakis, N., Kizys, R., 2015. Dynamic spillovers between commodity and currency markets. Int. Rev. Financ. Anal. 41, 303-319. https://doi.org/10.1016/j.irfa.2015.01.016

Awartani, B., Maghyereh, A. I., 2013. Dynamic spillovers between oil and stock markets in the Gulf Cooperation Council Countries. Energy Econ. 36, 28-42. https://doi.org/10.1016/j.eneco.2012.11.024

Baffes, J., 2007. Oil spills on other commodities. The World Bank. https://doi.org/10.1596/1813-9450-4333

Balc1lar, M., Demirer, R., Hammoudeh, S., Nguyen, D. K., 2016. Risk spillovers across the energy and carbon markets and hedging strategies for carbon risk. Energy Econ. 54, 159-172. https://doi.org/10.1016/j.eneco.2015.11.003

Batten, J. A., Ciner, C., Lucey, B. M., 2015. Which precious metals spill over on which, when and why? Some evidence. Appl. Econ. Lett. 22(6), 466-473. https://doi.org/10.1080/13504851.2014.950789

Benz, E., Trück, S., 2009. Modeling the price dynamics of $\mathrm{CO}_{2}$ emission allowances. Energy Econ. 31(1), 4-15. https://doi.org/10.1016/j.eneco.2008.07.003

Berta, N., Gautherat,E., Gun, O., 2017. Transactions in the European carbon market: a bubble of compliance in a whirlpool of speculation. Cam. J. Econ. 41(2), 575-593. https://doi.org/10.1093/cje/bew041

Boersen, A., Scholtens, B., 2014. The relationship between European electricity markets and emission allowance futures prices in phase II of the EU (European Union) emission trading scheme. Energy, 74, 585-594. https://doi.org/10.1016/j.energy.2014.07.024

Brunnermeier, M., K., Pedersen, L., H., 2009. Market liquidity and funding liquidity. Rev. Financ. Stud. 22(6), 22012238. https://doi.org/10.1093/rfs/hhn098

Bunn, D. W., Fezzi, C., 2008. A vector error correction model of the interactions among gas, electricity and carbon prices: an application to the cases of Germany and the United Kingdom. Markets for carbon and power pricing in Europe: Theoretical issues and empirical analyses, 145-159.

Cashin, P., Céspedes, L., F., Sahay, R., 2004. Commodity currencies and the real exchange rate. J. Deve. Econ. 75(1), 239-268. https://doi.org/10.1016/j.jdeveco.2003.08.005

Chan-Lau, M. J. A., 2017. Variance decomposition networks: Potential pitfalls and a simple solution. International Monetary Fund. http://dx.doi.org/10.2139/ssrn.2883119

Chang, E.C., Kim, C.W., 1988. Day-of-Week Effects and Commodity Price Changes. J. Futur. Mark. 8(2), 229-241.

Chang, T., H., Su, H., M., 2010. The substitutive effect of biofuels on fossil fuels in the lower and higher crude oil price periods. Energy, 35(7), 2807-2813. https://doi.org/10.1016/j.energy.2010.03.006

Chevallier, J., 2009. Carbon futures and macroeconomic risk factors: A view from the EU ETS. Energy Econ. 31(4), 614-625. https://doi.org/10.1016/j.eneco.2009.02.008

Chevallier, J., 2011a. A model of carbon price interactions with macroeconomic and energy dynamics. Energy Econ. 33(6), 1295-1312. https://doi.org/10.1016/j.eneco.2011.07.012

Chevallier, J., 2011b. Macroeconomics, finance, commodities: Interactions with carbon markets in a data-rich model. Econ. Model. 28(1-2), 557-567. https://doi.org/10.1016/j.econmod.2010.06.016

Chevallier, J., 2012. Time-varying correlations in oil, gas and $\mathrm{CO}_{2}$ prices: an application using BEKK, CCC and DCC-MGARCH models. Appl. Econ. 44(32), 4257-4274. https://doi.org/10.1080/00036846.2011.589809

Creti, A., Jouvet, P. A., Mignon, V., 2012. Carbon price drivers: Phase I versus Phase II equilibrium. Energy Econ. 34(1), 327-334. https://doi.org/10.1016/j.eneco.2011.11.001

Das, D., Bhowmik, P., Jana, R. K., 2018. A multiscale analysis of stock return co-movements and spillovers: Evidence from Pacific developed markets. Physica A. 502, 379-393. https://doi.org/10.1016/j.physa.2018.02.143

Daskalakis, G., Psychoyios, D., Markellos, R. N., 2009. Modeling $\mathrm{CO}_{2}$ emission allowance prices and derivatives: Evidence from the European trading scheme. J. Bank. Financ. 33(7), 1230-1241. https://doi.org/10.1016/j.jbankfin.2009.01.001

Davis, S. J., 2016. An index of global economic policy uncertainty (No. w22740). National Bureau of Economic Research. https://doi.org/10.3386/w22740

Diebold, F.X., Yllmaz, K., 2009. Measuring financial asset return and volatility spillovers with application to global equity markets. Econ. J. 119, 158-171. https://doi.org/10.1111/j.1468-0297.2008.02208.x 
Diebold, F.X., Yılmaz, K., 2012. Better to give than to receive: predictive directional measurement of volatility spillovers. Int. J. Forecast 28, 57-66. https://doi.org/10.1016/j.ijforecast.2011.02.006

Diebold, F.X., Yllmaz, K., 2014. On the network topology of variance decompositions: measuring the connectedness of financial firms. J. Econ. 182 (1), 119-134. https://doi.org/10.1016/j.jeconom.2014.04.012

Dubois, M., Louvet, P., 1996. The day-of-the-week effect: The international evidence. J. Bank. Financ. 20(9),14631484. https://doi.org/10.1016/0378-4266(95)00054-2

Ewing, B. T., Malik, F., 2017. Modelling asymmetric volatility in oil prices under structural breaks. Energy Econ. 63, 227-233. https://doi.org/10.1016/j.eneco.2017.03.001

Fama, E.F., French, K.R., 1989. Business conditions and expected returns on stocks and bonds. J. Financ. Econ. 25 (1), 23-49. https://doi.org/10.1016/0304-405X(89)90095-0

Forsberg, L., Ghysels, E., 2007. Why do absolute returns predict volatility so well? J. Financ. Econ. 5(1), 31-67. https://doi.org/10.1093/jifinec/nbl010

Graham, M., Hasselgren, A., Peltomäki, J., 2016. Using CO ${ }^{2}$ Emission Allowances in Equity Portfolios. In Ramiah, V., Gregoriou, G.N. (eds.), Handbook of Environmental and Sustainable Finance, Elsevier Inc., 359-370.

Hammoudeh, S., Lahiani, A., Nguyen, D. K., Sousa, R. M., 2015. An empirical analysis of energy cost pass-through to $\mathrm{CO}_{2}$ emission prices. Energy Econ., 49, 149-156. https://doi.org/10.1016/j.eneco.2015.02.013

Hintermann, B., 2010. Allowance price drivers in the first phase of the EU ETS. J. Envir. Econ. Manag. 59(1), 4356. https://doi.org/10.1016/j.jeem.2009.07.002

Inclan, C., Tiao, G. C., 1994. Use of cumulative sums of squares for retrospective detection of changes of variance. J. Am. Stat. Assoc. 89(427), 913-923. https://doi.org/10.1080/01621459.1994.10476824

Inoue, A., Jin, L., Rossi, B., 2014. Window selection for out-of-sample forecasting with time-varying parameters. Discussion Paper 10168, Centre for Economic Policy Research, London.

Irwin, S., H., Sanders, D., R., 2011. Index funds, financialization, and commodity futures markets. Appl. Econ. Pers. Poli. 33(1), 1-31. https://doi.org/10.1093/aepp/ppq032

Ji, Q., Zhang, D., Geng, J. B., 2018. Information linkage, dynamic spillovers in prices and volatility between the carbon and energy markets. J. Clean. Prod. 198, 972-978. https://doi.org/10.1016/j.jclepro.2018.07.126

Kanamura, T., 2016. Role of carbon swap trading and energy prices in price correlations and volatilities between carbon markets. Energy Econ. 54, 204-212. https://doi.org/10.1016/j.eneco.2015.10.016

Keppler, J. H., Mansanet-Bataller, M., 2010. Causalities between $\mathrm{CO}_{2}$, electricity, and other energy variables during phase I and phase II of the EU ETS. Energy Policy, 38(7), 3329-3341. https://doi.org/10.1016/j.enpol.2010.02.004

Khalifa, A.A., Hammoudeh, S., Otranto, E., 2014. Patterns of volatility transmissions within regime switching across GCC and global markets. Inter. Rev. Econ. Financ. 29, 512-524. https://doi.org/10.1016/j.iref.2013.08.002

Khalifa, A.A., Miao, H., Ramchander, S., 2011. Return distributions and volatility forecasting in metal futures markets: Evidence from gold, silver, and copper. J. Futur. Mark. 31 (1), 55-80. https://doi.org/10.1002/fut.20459

Khalfaoui, R., Boutahar, M., Boubaker, H., 2015. Analyzing volatility spillovers and hedging between oil and stock markets: Evidence from wavelet analysis. Energy Econ. 49, 540-549. https://doi.org/10.1016/j.eneco.2015.03.023

Kilian, L., 2009. Not all oil price shocks are alike: Disentangling demand and supply shocks in the crude oil market. Am. Econ. Rev. 99(3), 1053-69. https://doi.org/10.1257/aer.99.3.1053

Koch, N., 2014. Dynamic linkages among carbon, energy and financial markets: a smooth transition approach. Appl. Econ. 46(7), 715-729. https://doi.org/10.1080/00036846.2013.854301

Kodres, L. E., Pritsker, M., 2002. A rational expectations model of financial contagion. J. Financ. 57(2), 769-799. https://doi.org/10.1111/1540-6261.00441

Koop, G., Pesaran, M.H., Potter, S.M., 1996. Impulse response analysis in nonlinear multivariate models. J. Econ. 74 (1), 119-147. https://doi.org/10.1016/0304-4076(95)01753-4

Kumar, S., Managi, S., Matsuda, A., 2012. Stock prices of clean energy firms, oil and carbon markets: A vector autoregressive analysis. Energy Econ. 34(1), 215-226. https://doi.org/10.1016/j.eneco.2011.03.002

Lanne, M., Nyberg, H., 2016. Generalized forecast error variance decomposition for linear and nonlinear multivariate models. Oxford B. Econ. Stat. 78(4), 595-603. https://doi.org/10.1111/obes.12125

Lundgren, A. I., Milicevic, A., Uddin, G. S., Kang, S. H., 2018. Connectedness network and dependence structure mechanism in green investments. Energy Econ. 72, 145-153. https://doi.org/10.1016/j.eneco.2018.04.015

Ma, J., Vivian, A., Wohar, M. E., 2019. What Drives Commodity Returns? Market, Sector or Idiosyncratic Factors. Oxford B. Econ. Stat. online.

Mansanet-Bataller, M., Pardo, A., Valor, E., 2007. $\mathrm{CO}_{2}$ prices, energy and weather. Energy J. 28(3). https://doi.org/10.5547/ISSN0195-6574-EJ-Vol28-No3-5

Marimoutou, V., Soury, M., 2015. Energy markets and $\mathrm{CO}_{2}$ emissions: Analysis by stochastic copula autoregressive 
model. Energy, 88, 417-429. https://doi.org/10.1016/j.energy.2015.05.060

Oberndorfer, U., 2009. Energy prices, volatility, and the stock market: Evidence from the Eurozone. Energy Policy, 37(12), 5787-5795. https://doi.org/10.1016/j.enpol.2009.08.043

Oestreich, A. M., Tsiakas, I., 2015. Carbon emissions and stock returns: Evidence from the EU Emissions Trading Scheme. J. Bank. Financ. 58, 294-308. https://doi.org/10.1016/j.jbankfin.2015.05.005

Pesaran, M. H., Shin, Y., 1998. An autoregressive distributed-lag modelling approach to cointegration analysis. Econ. Soci. Monog. 31, 371-413.

Ranta, M., 2013. Contagion among major world markets: a wavelet approach. Inter. J. Manag. Financ. 9(2), 133-149. https://doi.org/10.1108/17439131311307556

Reboredo, J. C. (2013). Modeling EU allowances and oil market interdependence. Implications for portfolio management. Energy Econ. 36, 471-480. https://doi.org/10.1016/j.eneco.2012.10.004

Reboredo, J. C. (2014). Volatility spillovers between the oil market and the European Union carbon emission market. Econ. Model. 36, 229-234. https://doi.org/10.1016/j.econmod.2013.09.039

Sadorsky, P., 2014. Modeling volatility and correlations between emerging market stock prices and the prices of copper, oil and wheat. Energy Econ. 43, 72-81. https://doi.org/10.1016/j.eneco.2014.02.014

Singh, V. K., Kumar, P., Nishant, S., 2019. Feedback spillover dynamics of crude oil and global assets indicators: A system-wide network perspective. Energy Econ. 80, 321-335. https://doi.org/10.1016/j.eneco.2019.01.005

Shapley, L. S., 1953. A value for n-person games. Contri. Theory Games, 2(28), 307-317.

Sousa, R., Aguiar-Conraria, L., Soares, M. J., 2014. Carbon financial markets: A time-frequency analysis of CO2 prices. Physica A. 414, 118-127. https://doi.org/10.1016/j.physa.2014.06.058

Subramaniam, N., Wahyuni, D., Cooper, B. J., Leung, P., Wines, G., 2015. Integration of carbon risks and opportunities in enterprise risk management systems: evidence from Australian firms. J. Clean. Prod. 96, 407417. https://doi.org/10.1016/j.jclepro.2014.02.013

Tan, X. P., Wang, X. Y., 2017. Dependence changes between the carbon price and its fundamentals: A quantile regression approach. Appl. Energy, 190, 306-325. https://doi.org/10.1016/j.apenergy.2016.12.116

Tang, K., Xiong, W., 2012. Index investment and the financialization of commodities. Financ. Anal. J. 68(6), 54-74. https://doi.org/10.2469/faj.v68.n6.5

Tian, Y., Akimov, A., Roca, E., Wong, V., 2016. Does the carbon market help or hurt the stock price of electricity companies? Further evidence from the European context. J. Clean. Prod. 112, 1619-1626. https://doi.org/10.1016/j.jclepro.2015.07.028

Torrence, C., Compo, G., P., 1998. A practical guide to wavelet analysis. Bull. Amer. Meteor. Soci. 79(1), 61-78. https://doi.org/10.1175/1520-0477(1998)079\%3C0061:APGTWA\%3E2.0.CO;2

Uddin, G. S., Hernandez, J. A., Shahzad, S. J. H., Hedström, A., 2018. Multivariate dependence and spillover effects across energy commodities and diversification potentials of carbon assets. Energy Econ.71, 35-46. https://doi.org/10.1016/j.eneco.2018.01.035

Wang, Y., Guo, Z., 2018. The dynamic spillover between carbon and energy markets: New evidence. Energy, 149, 24-33. https://doi.org/10.1016/j.energy.2018.01.145

Wang, X., Wang, Y., 2019. Volatility spillovers between crude oil and Chinese sectoral equity markets: Evidence from a frequency dynamics perspective. Energy Econ. 80, 995-1009. https://doi.org/10.1016/j.eneco.2019.02.019

Wei, C. C., Lin, Y. G., 2016. Carbon Future Price Return, Oil Future Price Return and Stock Index Future Price Return in the US. Int. J. Energy Econ. Policy, 6(4), 655-662.

Wen, X., Bouri, E., Roubaud, D., 2017. Can energy commodity futures add to the value of carbon assets. Econ. Model. 62, 194-206. https://doi.org/10.1016/j.econmod.2016.12.022

Yu, L., Li, J., Tang, L., Wang, S., 2015. Linear and nonlinear Granger causality investigation between carbon market and crude oil market: A multi-scale approach. Energy Econ. 51, 300-311. https://doi.org/10.1016/j.eneco.2015.07.005

$\mathrm{Yu}$, J., Mallory, M. L., 2014. Exchange rate effect on carbon credit price via energy markets. J. Int. Money Financ. 47, 145-161. https://doi.org/10.1016/j.jimonfin.2014.04.010

Zachmann, G., 2013. A stochastic fuel switching model for electricity prices. Energy Econ. 35, 5-13. https://doi.org/10.1016/j.eneco.2012.06.019

Zhang, Y. J., Sun, Y. F., 2016. The dynamic volatility spillover between European carbon trading market and fossil energy market. J. Clean. Prod. 112, 2654-2663. https://doi.org/10.1016/j.jclepro.2015.09.118

Zhang, B., Wang, P., 2014. Return and volatility spillovers between China and world oil markets. Econ. Model. 42, 413-420. https://doi.org/10.1016/j.econmod.2014.07.013

Zheng, Z., Xiao, R., Shi, H., Li, G., Zhou, X., 2015. Statistical regularities of Carbon emission trading market: Evidence from European Union allowances. Physica A, 426, 9-15. https://doi.org/10.1016/j.physa.2015.01.018 
Zhu, B., Chevallier, J., Ma, S., Wei, Y., 2015. Examining the structural changes of European carbon futures price 2005-2012. Appl. Econ. Lett. 22(5), 335-342. https://doi.org/10.1080/13504851.2014.943875 